\title{
WestVirginiaUniversity
}

THE RESEARCH REPOSITORY @ WVU

Graduate Theses, Dissertations, and Problem Reports

2001

\section{Parent distress, parent behavior, and infant distress during pediatric immunizations}

\author{
Rebecca Suzanne Bernard \\ West Virginia University
}

Follow this and additional works at: https://researchrepository.wvu.edu/etd

\section{Recommended Citation}

Bernard, Rebecca Suzanne, "Parent distress, parent behavior, and infant distress during pediatric immunizations" (2001). Graduate Theses, Dissertations, and Problem Reports. 886.

https://researchrepository.wvu.edu/etd/886

This Thesis is protected by copyright and/or related rights. It has been brought to you by the The Research Repository @ WVU with permission from the rights-holder(s). You are free to use this Thesis in any way that is permitted by the copyright and related rights legislation that applies to your use. For other uses you must obtain permission from the rights-holder(s) directly, unless additional rights are indicated by a Creative Commons license in the record and/ or on the work itself. This Thesis has been accepted for inclusion in WVU Graduate Theses, Dissertations, and Problem Reports collection by an authorized administrator of The Research Repository @ WVU. For more information, please contact researchrepository@mail.wvu.edu. 
Parent Distress, Parent Behavior, and Infant Distress during Pediatric Immunizations

\title{
Rebecca S. Bernard
}

\author{
Thesis submitted to the College of Arts and Sciences \\ at West Virginia University \\ in partial fulfillment of the requirements \\ for the degree of
}

\author{
Masters of Arts \\ in \\ Psychology
}

\author{
Lindsey Cohen, Ph.D., Chair \\ Katherine Karraker, Ph.D. \\ Tracy Morris, Ph.D. \\ Department of Psychology \\ Morgantown, West Virginia \\ 2001
}

Keywords: parent distress, infant distress, parent behavior, pediatric procedures 


\begin{abstract}
Parent Distress, Parent Behavior, and Infant Distress during Pediatric Immunizations
\end{abstract}

\title{
Rebecca S. Bernard
}

Infant procedural distress historically has been ignored, and the importance of reducing infant distress only recently has been addressed. To understand and manage infant procedural distress, it is essential to examine the correlates and potential predictors of this distress. The purpose of this study was to examine the effects of parent distress on infant procedural distress, the effects of parent behavior on infant distress, and the combined impact of parent distress and behavior on infant distress for 37 parent-infant dyads. Results demonstrated that infant measures were not intercorrelated, only parent self-report measures were intercorrelated, and several measures of parent distress correlated with measures of infant distress. Additionally, hugging was positively associated, whereas distraction (during the immunization phase) was negatively associated with infant distress. Finally, several parent behaviors were negatively correlated with parent distress measures. Several treatment implications and recommendations for future research are discussed. 


\section{Dedication}

This manuscript is dedicated to my grandparents: my grandfather, Carl Mills, who taught me silent strength, my grandmother, Judy Mills, who taught me how to laugh even during tough times, and my 80-years-young grandmother, Shirley Bernard, whose interesting life stories have taught me that you can do anything if you set your mind to it. Thank you and I love you all. 


\section{Acknowledgements}

First and foremost, I would like to thank my advisor, Dr. Lindsey Cohen, for his guidance and patience. His diligence, dedication, and ability to endure multiple unexpected visits to his office for help were essential for the sake of my thesis and my sanity. I would also like to thank my other thesis committee members, Dr. Katherine Karraker and Dr. Tracy Morris for their expertise, direction, and efforts.

Thanks are also due to my parents for their unwavering faith and support, my WVU friends (especially those originally from WSU) for lending an open ear when needed, all of my wonderfully reliable coders, Kenna Clifton for sharing graduate school horror stories with me, and Chris Jacob for keeping me focused on the big picture. 
Table of Contents

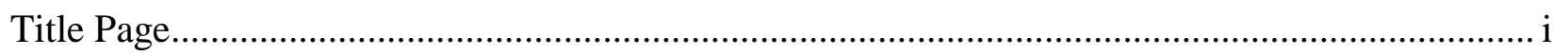

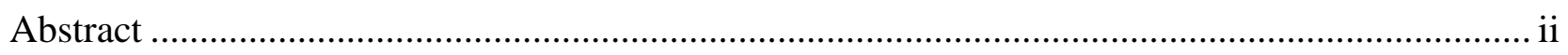

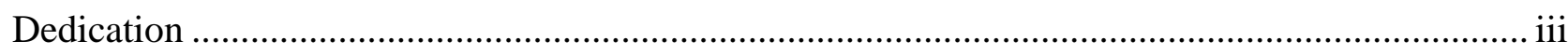

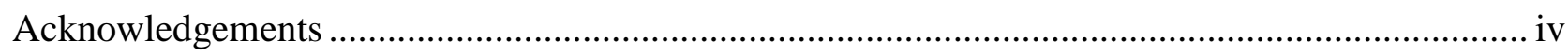

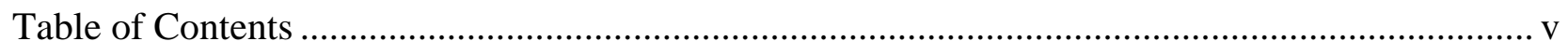

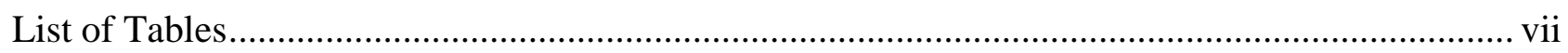

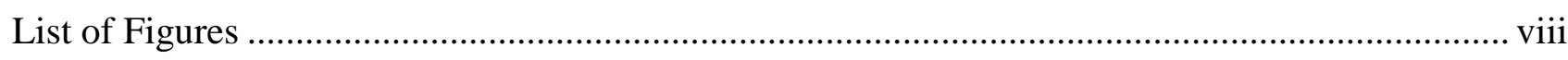

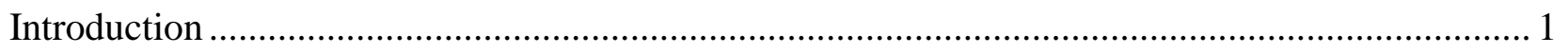

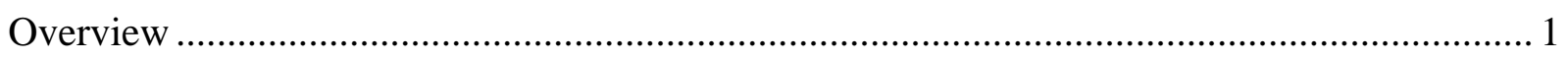

Neglect of Infants' Procedural Distress ....................................................................... 1

Recognition of Infants' Procedural Distress ............................................................... 1

Long-Term Effects of Infants' Procedural Distress .................................................... 5

Treatment of Infants' Procedural Distress ................................................................. 5

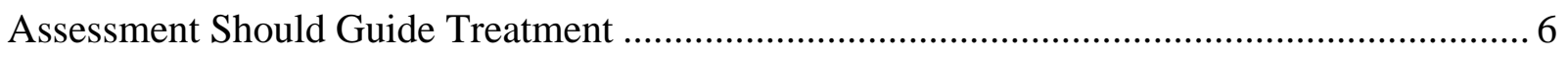

Preschoolers' Procedural Distress as a Model .............................................................. 6

Parents' Distress during Preschoolers' Procedures ....................................................... 7

Parents’ Behavior during Preschoolers' Procedures .................................................. 8

Treatment of Preschoolers' Procedural Distress ..................................................... 9

Combined Effects of Parents' Distress and Behavior on Preschoolers' Distress ................ 10

Parents’ Distress and Behavior during Infants' Procedural Distress .................................... 11

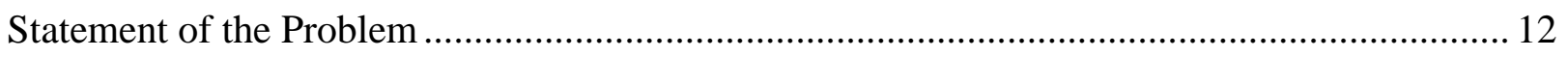

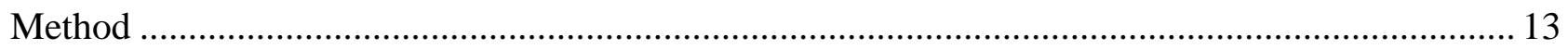




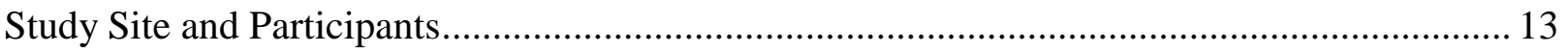

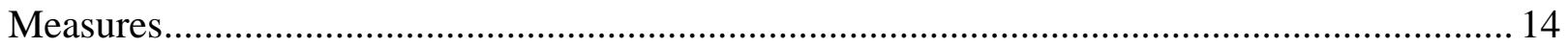

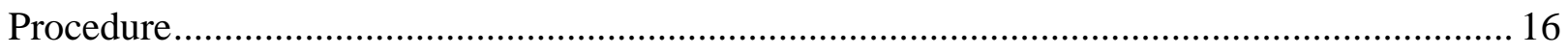

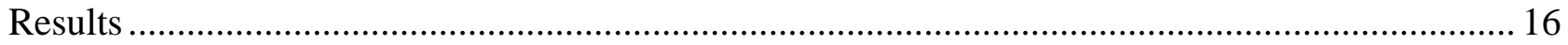

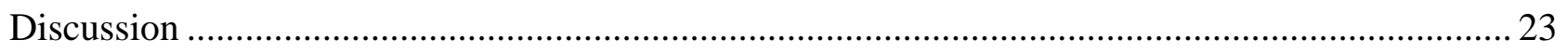

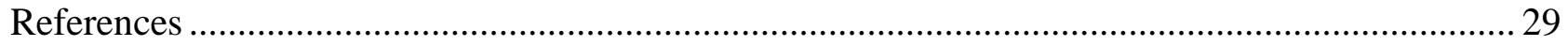

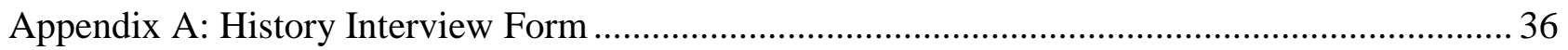

Appendix B: Parent Post-Procedure Questionnaire ........................................................ 37

Appendix C: Nurse Post-Procedure Questionnaire ............................................................ 38

Appendix D: Modified Behavior Pain Scale ....................................................................... 39

Appendix E: Measure of Adult and Infant Soothing and Distress .......................................... 40

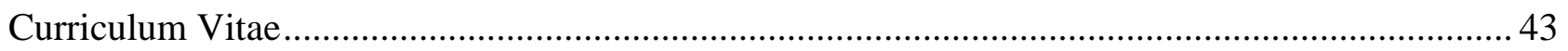




\section{List of Tables}

Table 1: Means and Standard Deviations for the Measures of Parent and Infant Distress .............. 17

Table 2: Correlations Among the Measures of Parent and Infant Distress ................................. 18

Table 3: Means, Standard Deviations, Minimums, and Maximums of the Rates of Each Parent

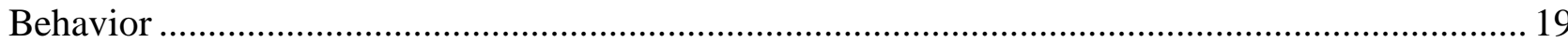

Table 4: Correlations among the Parent Behaviors and the Measures of Parent and Infant

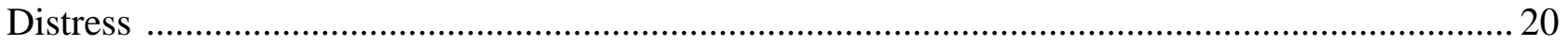

Table 5: Means and Standard Deviations for MBPS and MAISD by Phase ................................ 23 


\section{List of Figures}

Figure 1: Diagram of the mediating role played by parent behavior in the relations among parent

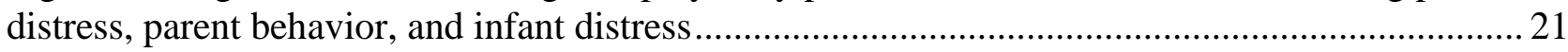


Parent Distress, Parent Behavior, and Infant Distress during Pediatric Immunizations

\section{Overview}

Pediatric psychology research addresses behavioral issues related to children's medical conditions. One area of research that cuts across different medical conditions is the examination of distress associated with invasive medical procedures. Research in pediatric procedural distress primarily has targeted children of preschool age and older, leaving a dearth of studies examining infants' procedural distress. Based on findings from the preschool procedural distress literature, I examined whether parent distress is associated with infant distress, whether parent behavior is associated with infant distress, and whether parent behavior mediates the relation between parent distress and infant distress.

In this manuscript, I examine the history and current studies addressing infant procedural distress. First, I provide general background information about infant procedural distress, the negative effects distress has on infants, and how infant distress has been assessed and treated. Next, I discuss the literature examining the impact of parent distress and behavior on preschooler distress, and present the literature on treatments for both parent and preschooler distress. Finally, I review the handful of studies that have examined parent distress and behavior during infant medical procedures.

\section{Neglect of Infants’ Procedural Distress}

Infants are subjected to numerous invasive medical procedures soon after being born (e.g., heel sticks) and regularly throughout infancy (e.g., immunizations); however, there is surprisingly little research in the assessment or treatment of infant medical procedural distress. In fact, infant procedural distress has been both understudied and undertreated (Anand \& Craig, 1996), and the most neglected area is outpatient procedures such as immunizations, which are common occurrences in the first few years of life (Porter, Wolf, Gold, Lotsoff, \& Miller, 1997).

There are several reasons for this dearth in the literature. Until recently, the general consensus was that infants did not experience pain to the same degree as older individuals. This idea is due in part to the fact that it was assumed that infants' nervous systems were too immature to perceive acute pain until twelve months of age (Derbyshire, 1999). It also was believed that infants could not remember early postnatal experiences; thus, pain experienced early in life would not have later adverse effects (Swafford \& Allen, 1968; Zimmermann \& Torrey, 1965). Compounding the issue, there are concerns about the risks of using analgesics with young children undergoing medical procedures (e.g., Hatch, 1987). Finally, research with infants has been complicated by the fact that infants cannot verbalize their distress (Craig, McMahon, Morison, \& Zaskow, 1984).

\section{Recognition of Infants' Procedural Distress}

Although infants' procedural distress historically has been neglected and misunderstood, there has been a recent surge of attention to infants' reactions to painful stimuli, and almost all of the prior misconceptions about infant distress have been refuted. First, researchers have 
demonstrated that infant procedural distress can accurately be assessed in a variety of ways, such as with behavioral and physiological measures (for a review, see Finley \& McGrath, 1998). For example, Craig and colleagues argued that infants' facial expression is a valid and reliable indicant of distress (Grunau \& Craig, 1987). Along these lines, Grunau and Craig developed the Neonatal Facial Coding System (NFCS), which consists of 10 facial movements indicative of infant distress expression (e.g., eyes squeezed, taut cupped tongue). Using the NFCS, Grunau and Craig (1987) found that five of these facial movements were found to consistently occur during heel lancing. Moreover, the same five facial actions have been consistently related to infant distress during injections (Grunau, Johnston, \& Craig, 1990).

Lilley, Craig, and Grunau (1997) used the NFCS to examine infant facial reactions during routine immunizations. Infants were stratified across five age groups: 2 months, 4 months, 6 months, 12 months, and 18 months of age. Results indicated an age-related variation in distress behavior across groups. Specifically, the 2-month-old infants demonstrated significantly greater distress than all except for the 18-month-old infants. The authors suggested that these results might be explained by either a developmental decrease in sensitivity or an increase in inhibitory control. Additionally, 4-month-olds recovered from the injection the fastest, suggesting a decrease in the amount of distress expressed between 2 and 4 months of age. This possibly is due to physical maturation and/or maturation of the mechanisms that inhibit the transmission of pain. The authors further suggested that an increase in the cognitive abilities of older infants could cause a complex emotional reaction that may explain why older infants have higher distress scores than 4-month-old infants. Results of this study demonstrated three things: infants exhibit distress during medical procedures, facial coding schemes such as the NFCS can identify and measure infant distress, and there is age-related variation in distress behavior. Additionally, the authors noted that, similar to past studies, temperament was not related to infant distress expression.

Two things should be noted about the Lilley et al. (1997) study. First, it is surprising that temperament was found to be unrelated to infant distress because it makes intuitive sense that infant temperament should play a role in infant distress, both perceived and expressed. Thus, the previously mentioned lack of temperament findings potentially could be due to measurement problems rather than a null relation with infant distress. For example, many of the temperament scales are long and difficult to administer as part of a research protocol, and the shorter scales might not adequately tap all of the temperament domains. Second, the spike seen in child distress behavior at 18 months of age is unusual. The work of Izard and colleagues might help explain this phenomenon. For example, Izard, Hembree, Dougherty, and Spizzirri (1983) assessed the facial expressions of infants ranging from 2 to 19 months of age during acute medical procedures. They concluded that acute pain produces an immediate distress expression as well as an immediate anger expression that increases with age. Thus, the behavioral elevation of the 18month-old infants in the Lilley et al. (1997) study might reflect the combination of distress and anger.

Body movement also has been shown to reflect infant distress (for a review see McGrath, 1998). In a study by Craig et al. (1984), one of the behaviors used to examine distress in infants receiving injections was molar body movement. Results indicated that children demonstrated distress through torso rigidity and withdrawal from the injection as well as kicking and thrashing. 
A later study also utilized body movements as one of the measures of infant distress during heel lancing procedures (Craig, Whitfield, Grunau, Linton, \& Hadjistavropoulos, 1993). Using the Infant Body Coding System, movements of the hands and feet (e.g., flexion, extension), of the limbs (e.g., jerky, well-modulated), of the head (e.g., head turn, neck flexion), and of the torso (e.g., twisting, arching) were coded. Infants demonstrated more vigorous body activity to the heel lance than other events (e.g., baseline activities such as warming the foot to prepare it for the lance), thus indicating that they are able to differentiate invasive events from innocuous ones. This finding provides added support for including body movements, in addition to facial expression, in the examination of infant distress behavior.

Crying, possibly the most salient infant distress behavior, has been examined as another measure of overt infant distress. Latency, duration, intensity, and frequency of cry have all been used to assess infant distress (Taddio, Nulman, Koren, Stevens, \& Koren, 1995). For example, in a study of 50 newborns undergoing a heel stick, one of the measures used to assess infant distress was cry (Gunnar, Porter, Wolf, Rigatuso, \& Larson, 1995). Almost all subjects responded to the heel stick, with the average infant crying for $63 \%$ of the procedure. Similarly, in another study of infants undergoing heel sticks, percentage of crying was consistently higher during the heel stick than during non-invasive tactile stimulation (Owens \& Todt, 1984). The authors concluded that infants experience distress during invasive medical procedures and that this distress can reliably be assessed via cry. However, even though cry has been used in several studies to assess overt infant distress, McGrath (1998) points out two difficulties with this measure. First, not all infants respond to pain by crying. Second, specificity of the cry is a problem; it is difficult to discriminate between different types of cry (e.g., anger from pain). Until more sophisticated analyses of cry are conducted, this measure may be used best in conjunction with other measures of infant distress.

Although several specific behavioral measures of infant distress have been developed, a multidimensional scale that incorporates several behaviors indicative of distress might be preferable. The Modified Behavioral Pain Scale (MBPS; Taddio, Nulman, Goldbach, \& Ipp, 1994) appears especially promising because it taps numerous indicators of infant distress behavior including facial expression, cry, and body movement. This scale was developed specifically to assess injection pain in infants and initial studies with the MBPS have shown that it is a valid and reliable measure (Taddio et al., 1995). Moreover, in his review of behavioral scales that measure distress in infants, McGrath (1998) stated that the MBPS has demonstrated excellent psychometric properties. In a study of ninety-six 4- to 6-month-old infants undergoing immunizations, Taddio and colleagues used the MBPS, the pediatrician's (who gave the injection) visual analog scale (VAS) score, and a trained observer's VAS score to assess infant distress (Taddio et al., 1995). Half of the infants received a local anesthetic cream, and the other half received a placebo prior to the immunization. Results revealed that post-procedural distress scores were lower in infants who received the analgesic cream. Additionally, the construct validity of the MBPS was established by correlating it with the pediatrician and observer VAS scores. The MBPS was strongly correlated with both the trained observer, $r(96)=0.68, p<$ 0.001 , and pediatrician, $r(96)=0.74, p<0.001$. The authors concluded that the MBPS effectively measures infant distress behavior and is sensitive to treatment effects. 
In addition to various behavioral measures, physiological measures have been used to measure infant distress. For example, in a study of infants undergoing inoculation, heart rate was found to initially drop and then rise and remain elevated for more than one minute beyond the injection (Johnston \& Strada, 1986). Owens and Todt (1984) found similar results in their study of infants undergoing a heel lance procedure. Heart rate was found to increase after the procedure and remain above baseline levels for approximately three and a half minutes. Blood pressure also has been found to increase during and after pain (Anand, 1990). Less conclusive results have been found with the use of respiratory rate as a measure of distress. Some studies have indicated that respiratory rate increases during painful events (Stevens, Johnston, \& Grunau, 1995) whereas others have found a decrease in respiratory rate (Craig et al., 1993).

In addition to these commonly used physiological measures, researchers have examined other physical indices of distress. Vagal tone, which typically is assessed using respiratory sinus arrhythmia and measured with an electrocardiograph, has been linked to distress. High vagal tone is indicative of a slow, variable heart rate and greater parasympathetic input to the heart, and low vagal tone is indicative of a high, steady heart rate and less parasympathetic input to the heart (Sweet \& McGrath, 1998). Gunnar et al. (1995) found that vagal tone differed significantly across the phases (i.e., baseline, heel-stick procedure, recovery) of heel-stick procedures and was lowest during the heel stick. Additionally, vagal tone has been found to decrease significantly during infant circumcision (Porter, Porges, \& Marshall, 1988). Like vagal tone, oxygen saturation (usually measured by a pulse oximeter) has been found to decrease during painful procedures (Maxwell, Yaster, Wetzel, \& Niebyl, 1987). Both vagal tone and oxygen saturation have been shown to be associated with infant pain and are used to measure infant distress during medical procedures.

Relatively more invasive physiological measures of distress also have been used. For example, transcutaneous oxygen tension is measured through an electrode attached to the infant's skin. Using this measure, male infants undergoing circumcision were found to have decreased transcutaneous oxygen tension levels during the procedure (Rawlings, Miller, \& Engel, 1980). When using intracranial pressure as a measure of infant distress, pressure is measured in centimeters of water by placing a headband on the infant that contains a Ladd monitor with a fiber-optic probe that is placed over the anterior fontanel (Stevens \& Johnston, 1994). Increases in intracranial pressure have been associated with infant distress (Stevens, Johnston, \& Grunau, 1995).

Clearly, many of these physiological measures provide rich information about infant distress response; however, some are difficult and costly to use. In both clinical and research settings, practicality of the measure becomes an issue. Given the ease and noninvasive nature of measuring heart rate, it has emerged as the most viable and frequently used physiological measure of infant distress (Sweet \& McGrath, 1998, p. 78).

With studies indicating that there are several different modalities through which infants can demonstrate distress, many researchers have opted to use more than one avenue to measure infant distress. For example, in a study of 56 newborns undergoing a heel lance procedure, facial activity, body movements, and physiological measures were used to assess infant distress (Craig et al., 1993). Specifically, there was a significant difference in the overall level of facial activity 
between the baseline and heel lance periods. Additionally, body movements were the most vigorous during the procedure. Finally, the heel lance procedure consistently resulted in changes in the physiological measures relative to baseline. The authors concluded that both "preterm and full-term neonates clearly have the capacity to react to invasive pain and to communicate their distress to caretakers" (p. 295). Thus, by using several indices of infant distress, the authors were able to conduct a comprehensive examination of infant distress.

\section{Long-Term Effects of Infants’ Procedural Distress}

In addition to the research focusing on assessing infant distress behavior, studies have begun to demonstrate that medical distress sustained during infancy has long-term detrimental effects (e.g., Gunnar et al., 1995; Porter, Grunau, \& Anand, 1999; Taddio, Katz, Ilersich, \& Koren, 1997). Specifically, it has been argued that the physiological changes associated with pain during infancy cause structural changes in the developing nervous system, which in turn leads to heightened pain experience during future painful events (Porter et al., 1999). This position is supported by a recent study on the effects of neonatal circumcision on the infant's distress response during a later vaccination (Taddio et al., 1997). In this study, 87 infants undergoing either their 4-month or their 6-month vaccination were divided into three groups: infants who were uncircumcised, infants who received an analgesic cream before circumcision, and infants who received placebo before circumcision. Infant distress was assessed using facial action, cry duration, and visual analog scale scores. Results indicated that infants who had previously been circumcised without any analgesic medication had higher facial action, longer cry duration, and higher visual analog scale scores than infants who were previously circumcised with a topical anesthetic. The authors suggested that circumcision causes alterations in the infants' central neural processing of painful stimuli, which in turn results in long-lasting changes in infants' distress behavior. Specifically, noxious afferent input is transported from the periphery to the spinal cord, which induces sustained central nervous system sensitization. This then amplifies any subsequent input from the incision and causes increased pain after the operation. Although the specific mechanisms that cause long-lasting central neuronal changes are not understood fully, the results of the study provide evidence for this process. In short, early pain experience sensitizes infants to later pain. Other studies with rat pups (Ruda, Ling, Hohmann, Peng, \& Tachibana, 2000) and human infants (Gunnar et al., 1995) support this claim (for a review, see Porter et al., 1999). These provocative investigations highlight the importance of fully assessing and treating infant painful experiences.

\section{Treatment of Infants' Procedural Distress}

The research indicating that infants fully experience procedural distress, that distress behavior can be reliably assessed, and that distress may have deleterious long-term effects has caused a recent surge in the number of treatment outcome studies in this area. For example, interventions for infant procedural distress include sucrose ingestion (Barr et al., 1995; Herschel, Koshnood, Ellman, Maydew, \& Mittendorf, 1998; Johnston, Stremler, Stevens, \& Horton, 1997; Lewindon, Harkness, \& Lewindon, 1998), physical contact (Gray, Watt, \& Blass, 2000; Hallstrom, 1968; Korner \& Thoman, 1972), vestibular-proprioceptive stimulation (Korner \& Thoman, 1972), lidocaine-prilocaine patches or cream (Halperin, McGrath, Smith, \& Houston, 2000; McIntosh, van Veen, \& Brameyer, 1994), rocking (Campos, 1994; Johnston et al., 1997), 
providing pacifiers (Campos, 1994), and swaddling (Campos, 1989). Several of these treatments, seem to be based on folklore and intuition, and have yielded promising results. Whereas effective treatments might be developed via clinical experience and common sense, there are also advantages to constructing treatments based on preliminary thorough empirical assessments. For example, controlled research might uncover treatment avenues that would not otherwise be noted via casual observations.

\section{Assessment Should Guide Treatment}

Recently, researchers have argued that explicative studies should precede and guide the development of treatments (Blount, Bunke, \& Zaff, 2000). These researchers argue that understanding the factors that are related to and control a behavior are linked closely to treatment. In fact, to provide treatment without full understanding of the various factors involved in the problem can sometimes be dangerous and unethical (Blount, 1987). To avoid this potential hazard, it is important to conduct a comprehensive assessment of the problem (Roberts, 1992). Once broad problem areas have been established, the assessment then narrows on specific target behaviors and their controlling factors. After this phase of the process is complete, the best possible treatment avenue can be selected. The authors also stress the importance of treatment outcome research and state that this type of research is being neglected; however, in their opinion, this type of research should only be done after the proper assessments have been conducted.

In sum, some researchers feel that comprehensive assessments of the pertinent variables should be performed as a first step in pediatric distress management research. The findings from the explicative work should then guide the development of treatments for the population of interest. Thus, researchers in areas with well established controlling factors should focus on treatment outcome studies whereas researchers in relatively new areas should focus on assessment studies.

\section{Preschoolers' Procedural Distress as a Model}

Research examining preschooler procedural distress behavior has progressed in a systematic way, with the assessment work guiding the treatment studies (Blount et al., 2000). Based on numerous assessments of correlates of preschoolers' procedural distress, the primary variables repeatedly identified are parents' distress (e.g., Jay, Ozolins, Elliot, \& Caldwell, 1983) and parents' behavior (e.g., Frank, Blount, Smith, Manimala, \& Martin, 1995) during their child's procedure.

Before proceeding with the review of preschoolers' procedural distress, it is important to stress why the examination of distress and the variables associated with it is important. It could be argued that distress during medical procedures is not necessarily detrimental; after all, procedures are usually painful and upsetting. However, distress quickly becomes problematic if it impedes the procedure. For example, during bone marrow aspirations, children often resist treatment by kicking or screaming thus making the procedure very difficult to execute (Jay et al., 1983). Moreover, the extreme distress associated with pediatric medical procedures can lead to missed doctors appointments. A study by Reis (1997) found that children who are scheduled to 
receive three immunizations were more likely to miss their appointment than children who were to receive fewer injections. Considering the importance of immunizations for preventing serious illness, the understanding of distress related to the immunization process is imperative.

Parents' Distress during Preschoolers' Procedures. Parents' distress related to their child's medical situation has been researched in a myriad of situations. Research has indicated that merely being in a medical setting can be distress provoking for parents. Whelan \& Kirkby (1997) reported that $45 \%$ of parents rated themselves as very anxious about the hospitalization of their child. Ogilvie (1990) also examined the experiences of parents at stressful points during their child's hospitalization. Results of direct observations and interviews indicated that parents perceived many parts of the hospitalization process to be highly stressful. In fact, some research has suggested that parents report higher anxiety than their child (Ogilvie, 1990).

Aside from the general distress provoked by being in a medical setting, the pediatric medical procedures are very stressful for parents (Berenbaum \& Hatcher, 1990; Cohen, Blount, \& Panapoulos, 1997; Kaplan, Smith, Grobstein, \& Fishman, 1973). For example, in their 1996 study of parents of children with leukemia, Boyer and Barakat found that although mothers displayed very little overt distress, they reported feeling moderately distressed both before and after their child's lumbar puncture. In a comparison of parents of burn victims to parents whose children were undergoing other procedures, both groups were rated as highly distressed on measures of state anxiety and stress in general (Cella, Perry, Poag, Amand, \& Goodwin, 1988). Moreover, parents of burn victims had more prominent symptoms of depression, hopelessness, and avoidance. Other reports of specific symptomatology associated with having an ill child were found in a study of 89 Chinese families of children with cancer. Results revealed that parents often reported a loss of appetite, weight loss, problems sleeping, headaches, and dizziness (Martinson, Chiang, \& Yi-Hua, 1997).

Parents' distress during their child's procedure is difficult in the short-term, and research has suggested that it might have negative long-term effects. For example, Kazak and Barakat (1997) found a strong relation between parental stress experienced during their child's leukemia treatment procedures and parents' later adjustment. In this study, the authors showed that parents' distress levels were significantly higher than the normative population, and that their distress during their child's treatment was related to later parent Post Traumatic Stress Disorder symptomatology and state anxiety.

Parent distress related to their child's medical procedures, both in the short- and longterm, is a problem that needs to be addressed. In addition, parent distress negatively affects the child patient. Melnyk (1994) examined 108 mothers of children ages 2-5 years old who were hospitalized. In this study, mothers either received information about the typical behaviors of hospitalized children, information about strategies they could use to help their children cope, both types of information, or control information about hospital policies. Mothers who received either type of behavioral information reported less anxiety than mothers who received control information. Further, only children of mothers who received either type of behavioral information (or both types) were reported as exhibiting less negative behavior. In a study of 97 children undergoing orthopedic surgery, parent and child anxiety was assessed using an ageappropriate State Anxiety Inventory (LaMontagne, Hepworth, Byington, \& Chang, 1997). 
Results indicated that parents who had high preoperative anxiety typically had children with high preoperative anxiety. Other researchers have reported similar results of a positive relation between parent and child anxiety (e.g., Wright, Alpern, \& Leake, 1973).

Because of the high positive correlation between parent and child procedural distress, Jay et al. (1983) argue that parental distress during the child's medical procedure is one of the three strongest predictors of child distress. Although this research provides strong evidence for the impact of parent distress on child distress, it is important to note that in almost all of these studies, only self-report was used to assess parent distress; inclusion of other measures of parental distress (e.g., nurse report, heart rate) is essential to evaluate the situation fully. For example, it would be important to know whether the pediatric medical personnel, who might be in a position to comfort the parents, are cognizant of the parents' distress.

Given the recognition of high parent distress during children's procedures and its negative impact on child coping, it is not surprising that researchers strongly advocate for the direct treatment of parent distress during children's procedures (e.g., Kazak \& Barakat, 1997). Along these lines, Jay and Elliot (1990) developed a stress inoculation program specifically designed to reduce parental stress during their children's oncology procedures. This program included watching films that provided modeling of appropriate coping behaviors and education about leukemia, self-statement training, and relaxation training. Results of this study provided initial evidence for the efficacy of the stress inoculation program for decreasing parent distress. Specifically, parents reported less anxiety and had higher positive self-statement scores than parents in the other condition. Although no behavioral differences between the two groups were found, the authors noted that parents often are able to suppress obvious behavioral manifestations of distress and that the behavioral measure that they used might have been unable to pick up on subtle behavioral effects. Similar to Jay and Elliot, Campbell et al. (1992) used a stress management program to reduce distress levels in the parents of preschoolers undergoing cardiac catherization. In short, parents who had received stress management training, as compared to those who received brief supportive psychotherapy, reported less anxiety and their children exhibited more adaptive behaviors during stressful parts of the procedure.

Other attempts to reduce parent anxiety during children's procedures have included providing information to mothers to facilitate their preparation (e.g., Melnyk, 1995) and training parents to serve as coaches for their child (e.g., Manne et al., 1990). For example, both Peterson and Shigetomi (1981) and Zastowny, Kirschenbaum, and Meng (1986) examined the effect of using parents as coaches while their child was being prepared for surgery. Results indicated that teaching the parents coping skills decreased their feelings of anxiety and increased their feelings of competence. Several other researchers also have found that parental distress can be lowered if they are used as coaches during the procedure and this, in turn, is related to decreased child distress (Cohen et al., 1997; Manne et al., 1990).

Parents' Behavior during Preschoolers' Procedures. In addition to parent distress, parent behavior has been identified as a key aspect of preschooler procedural distress. In fact, maternal behavior has been shown to account for as much as 53\% of the variance in child distress (Frank et al., 1995). Initially, clinical observations revealed that certain parent behaviors are linked to their child's ability to cope with medical procedures. Jay et al. (1983) noted that parents who 
focused on mastery rather than avoidance of the procedure and who did not react in an anxious manner had children who coped more effectively and displayed less distress. Clinical observations such as these led researchers to begin examining other parent behaviors and their association with child distress. For example, Jacobsen et al. (1990) examined the relation of specific parent behaviors and child distress. Seventy 3- to 10-year-old pediatric cancer patients undergoing venipucture and their parents were assessed using self-report measures and an observational scale. Results indicated that parent explanation about the procedure was highly associated with child distress. In a study of 43 pediatric patients undergoing venipuncture, six adult behavior categories (e.g., explain, distract, and praise) were assessed for their relations to child behavior (Manne et al., 1992). Distraction was shown to have a beneficial effect on both child coping and child distress, whereas giving the child control of the procedure reduced only child crying. Other behaviors such as directives to cope had mixed results. If the child was calm at the outset of the procedure, then directives to cope were associated with more child distress, but if the child was upset at the outset, then commands to cope were associated with less child distress.

Whereas Jacobsen et al. (1990) and Manne et al. (1992) examined relatively few parent behaviors, other researchers have examined a range of parent behaviors. Blount stated that through the use of preliminary observation and sequential analysis he and his colleagues were able to identify antecedents and consequences of parent and child behavior in the medical setting (Blount et al., 2000). After initial research was conducted, the Child-Adult Medical Procedure Interaction Scale (CAMPIS; Blount et al., 1989) was created to further examine particular parent behaviors. In a study of 25 children between the ages of 5 and 13 years old who were diagnosed with acute lymphocytic leukemia, the CAMPIS was used to assess the associations among 17 parent vocalizations and child behavior (Blount et al., 1989). Results indicated that certain adult behaviors clearly were associated with either child coping or distress behaviors. Moreover, it was found that adults' reassuring comments, apologies to the child, giving control to the child, and criticizing the child usually preceded child distress. Further, when children engaged in distress behaviors, parents often responded with reassurance. On the other hand, child coping behaviors were associated with adult commands for the child to engage in coping behaviors, with nonprocedural talk with the child, and with humor. Based on these findings, Blount and colleagues $(1990,1997)$ revised the CAMPIS and formed two categories comprised of the individual parent behaviors: Adult Coping Promoting and Adult Distress Promoting.

In short, research has revealed that parent behaviors are highly associated with child distress behavior. Specifically, parents' reassuring comments, giving the child behavioral control, apologizing, empathetic comments, and criticism have been shown to be significantly positively associated with preschoolers' procedural distress. On the other hand, parents' distracting comments and commands to engage in coping have been shown to predict increased child coping and decreased procedural distress.

Treatment of Preschooler's Procedural Distress. Treatments aimed at reducing preschooler distress have been developed based on these assessment findings. For example, Cohen et al. (1997) encouraged parents and nurses to engage in high levels of distraction in order to reduce preschooler distress. This treatment outcome study demonstrated that parent distracting behavior was positively related to child coping and negatively related to child and their own 
distress. Similarly, Manne, Bakeman, Jacobsen, Gorfinkle, and Redd (1994) examined the effectiveness of distraction (use of a party blower) in reducing child distress during venipucture. Parents were instructed to coach their children to use the distraction technique. Like Cohen et al., Manne et al. found that use of distraction was significantly associated with less child crying. Research with other adults present during medical procedures have found that nurses trained to provide distraction resulted in lower distress for preadolescents when compared to a topical anesthetic or control (Cohen et al., 1999). Manne et al. (1990) used a more comprehensive behavioral intervention involving parent coaching, distraction, and positive reinforcement to decrease child distress during venipucture associated with cancer treatment. Twenty-three children who were known to require physical restraint during the procedure were assigned to either the behavioral intervention or to a control group. Results demonstrated that the behavioral intervention was successful in decreasing observed child distress, parent-rated child distress, and parents' own ratings of distress. Additionally, the need for physical restraint was significantly reduced.

In summary, two of the most important variables to be identified via the explicative studies of preschooler distress are parent distress and parent behavior (e.g., reassurance, distraction). Preschooler procedural distress treatment outcome studies based on this assessment work have resulted in effective and efficient interventions in addition to suggestions for adults as to how to assist children with medical procedural distress.

\section{Combined Effects of Parents' Distress and Behavior on Preschoolers' Distress. In} addition to recognizing the importance of parent distress and parent behavior in their own right, the interaction between the two also could be potentially beneficial or detrimental to the child's ability to adjust to hospitalization and medical procedures. Although most studies have examined either parent distress and/or parent behavior as separate variables associated with child distress, a few have examined the effects that these two variables have on each other. For example, maternal behavior in the medical treatment room prior to a medical examination was examined for 50 parents of children between the ages of 4 and 10 years (Bush, Melamed, Sheras, \& Greenbaum, 1986). Although the researchers were limited because they only used self-report to assess maternal anxiety, they did report that mothers with high trait anxiety had a tendency to ignore their children more than mothers with lower reported anxiety.

Bush and Cockrell (1987) studied the relation between maternal distress and parent behavior in their examination of the predictors of mothers' parenting behaviors. Fifty children between the ages of 4 and 10 years of age who were undergoing outpatient pediatric examinations participated in the study. Both child and parent anxiety were assessed with selfreport questionnaires and parent-child interactions were evaluated with an observational measure. The authors found that although self-reported anxiety was not directly related to child distress behavior, maternal trait anxiety was positively associated with maternal ignoring. In addition, maternal state anxiety was inversely associated with reassurance behavior. Consistent with prior studies, maternal reassurance and ignoring were positively associated with child distress. Of note, the authors did not examine the relations among all three variables - maternal behavior, maternal anxiety, and child distress. 


\section{Parents' Distress and Behavior during Infants' Procedural Distress}

Although there has been an explosion of studies assessing infant distress, and a handful of researchers have dabbled with different interventions to reduce infant distress, there is a paucity of studies evaluating any of the variables that might be correlates of infant procedural distress. This is especially surprising considering the attention to the correlates of preschooler distress, and how these findings have guided treatment development. Given the recognition of the critical role that parents play in mediating preschoolers' distress, coupled with common sense that infants are almost wholly dependent on their parents for comfort, it is disconcerting that parent behavior has received little attention in regard to its impact on infant procedural distress.

A review of the literature revealed that only three studies have examined parent behavior during infant procedural distress. First, Craig et al. (1984) evaluated maternal behavior during their infants' painful medical procedures. The 30 participating children were between 2 and 24 months of age and undergoing routine immunization injections. Since this article focused on developmental changes in the expression of infant distress, the main findings were about changes in distress expression. The authors found that age was related to distress behavior, with older infants using more descriptive language, more goal-directed movement, and displaying more anticipatory distress than infants less than 12 months old. The authors did detail several maternal behaviors (e.g., praise, distraction, soothing, procedural talk), which are the first descriptive accounts of mothers' behavior during infants' procedures. Although the authors acknowledge that both maternal behavior and distress would likely impact children's distress reactions, they did not examine the relations among these variables.

Second, Lewis and Ramsay (1999) examined the effects of maternal behavior on infant distress during routine inoculation. In this study, two groups of infants (with 55 and 74 participants respectively) were observed longitudinally at 2, 4, and 6 months of age. In the first study, the authors examined the relation between maternal soothing and infant cortisol (a physiological index of distress) and behavioral responses during inoculation, whereas in the second study they examined everyday infant distress (e.g., diaper change while in the pediatrician's office). In both studies, the authors reported that there was no evidence that the mothers' behaviors decreased infants' behavioral or cortisol response to the stressor. However, the authors noted that maternal soothing behaviors might not have been properly assessed with their four-point scale (none, low, moderate, high). In fact, the authors suggest a more finegrained analysis of maternal behavior in order to better assess maternal soothing. Additionally, although the authors postulated that other maternal behaviors might in fact be important in mediating infant distress, they did not assess other maternal behaviors or maternal anxiety. Given that research with preschoolers has demonstrated a strong association between both parental behavior and parental distress and child procedural distress, it is likely that parental behavior and parental distress might have influenced infant distress in this situation.

In the third study of parental behavior and infant procedural distress, Sweet and McGrath (1998) examined the verbal behavior of mothers and medical staff and the facial distress behavior of 60 infants receiving either their 6- or 18-month immunizations. The immunizations were video taped and later coded using the revised CAMPIS-R (Blount et al., 1997). Consistent with CAMPIS-R protocol, parent and staff vocalizations were categorized as coping-promoting 
(e.g., non-procedural talk, commands to engage in coping behavior), distress-promoting (e.g., apologies, reassuring comments), or neutral (e.g., non-procedural talk to adults, humor between adults). Infants' distress was coded via facial actions (e.g., brow bulge, eye squeeze, naso-labial furrow) with the Neonatal Facial Action Coding System (NFCS; Grunau \& Craig, 1987). Results indicated that maternal verbalizations classified as distress-promoting (e.g., reassurance) were predictive of increased infant distress behaviors and that mothers were more likely than staff members to use these distress-promoting vocalizations. Additionally, staff coping-promoting behavior (e.g., distraction) but not mother coping-promoting behavior was associated with decreased infant distress. Although this study demonstrates a relation between maternal behavior and infant distress, the authors used a scale developed for preschoolers and older children, which relies on verbalizations. Thus, nonverbal behaviors, such as rocking a baby, were not coded. In addition, the authors did not examine the role of parental distress.

In summary, the three studies of parent-infant interactions during painful medical procedures resulted in mixed findings. In my opinion, Sweet and McGrath's study is the most comprehensive of the three studies and revealed that maternal behavior is related to infant distress in a similar manner to how parent behavior is related to preschooler distress. Specifically, as expected, reassuring comments were positively correlated with infant distress, but, unlike the preschool literature, distracting comments by mothers were not found to relate to decreased infant distress. It is important to point out that none of these studies, or any other studies of infant procedural distress, provides information about parent distress. Given the importance of parent distress in relation to preschooler procedural distress, and the notion that infants are highly dependent on their parents for comfort during stressors, it is essential to evaluate parents' distress during infants' painful medical procedures. Further, none of these studies adequately assessed parents' behaviors during infants' procedures. Specifically, many of the nonverbal adult behaviors employed to soothe infants (e.g., rocking, hugging) were not evaluated.

\section{Statement of the Problem}

In summary, children and their parents find many aspects of hospitalization and medical procedures to be distressing; and parental distress is an important variable to consider in its own right, and also because it is strongly associated with child procedural distress. In fact, it has been suggested that parental distress during their children's procedures is detrimental to the child's coping abilities (e.g., Bush \& Cockrell, 1987). Also, there is research to suggest that it is especially important to examine the relation between parent distress and child distress in younger populations because younger children show a greater number and variety of distress behaviors than their older counterparts (Blount, Landolf-Fritsone, Powers, \& Sturges, 1991; Jay et al., 1993), and younger children are more dependent than older children on their parents for comfort. Moreover, recently it has been demonstrated that infants experience high levels of distress during medical procedures and that these painful medical procedures might also have long-term negative effects (e.g., Taddio et al., 1997).

Despite the evidence indicating the importance of assessing maternal behavior and distress during pediatric procedures, to date no studies systematically have examined parental behavior or distress during infant procedures. Thus, the purposes of this study were to examine 
1) whether parent distress is associated with infant distress, 2) whether parent behavior is associated with infant distress, and 3) whether parent behavior serves a mediating role between parent and infant distress.

A comprehensive assessment of the variables of interest was conducted. Parent distress was assessed with questionnaires examining their state anxiety levels, nurse rating of parent distress, self-report, and heart rate. Due to the lack of an adequate parent behavior measure in the literature, parent behavior was evaluated using an observational scale developed for this study. Infant distress was assessed with nurse and parent report measures, heart rate, and an established behavioral scale. It is important to note that measures of distress are conceptually different depending on the reporter. Thus, parent self-report of distress is a measure of felt distress, whereas nurse-report of parent and infant distress as well as the observational scale of infant distress is a measure of expressed distress. In an attempt to bridge the literature between infant and preschooler procedural distress, I included infants as young as 7 weeks to 1 year 11 months. This allowed for investigation of differences in parent behavior and child distress across age.

Hypotheses. 1) As has been found with preschoolers and older children, it was hypothesized that there would be a significant association between parent and infant procedural distress. In particular, parent distress was expected to correlate positively with infant distress across measures. 2) Consistent with the preschooler research, it was expected that parent behavior would group into 'comforting behaviors' and 'distracting behaviors.' Specifically, verbal reassurance, hugging, kissing, rubbing, and rocking were expected statistically to form the 'comforting behaviors' group, whereas distraction, offering a toy, offering a pacifier, offering food, nursing, and tickling would make up the 'distracting behaviors' group. 3) Paralleling prior research with older populations, parent comforting behaviors were expected to correlate with heightened infant distress whereas parent distracting behaviors were expected to be associated with diminished infant distress. 4) Finally, it was predicted that there would be a relation between parent distress and parent behavior, with parent behavior serving a mediating function in predicting child distress. Based on the relatively limited research looking at this relation, it was hypothesized that parents who have high distress would exhibit comforting behaviors, which in turn would predict heightened child distress. Conversely, parents experiencing low distress were expected to engage in distracting behaviors, and the children of these parents would have lower distress.

Method

\section{Study Site and Participants}

The study was conducted in a rural health department and two nurses administered all of the injections. Thirty-nine children, 18 boys and 19 girls, whose ages ranged from seven weeks to one year and eleven months $(M=0.78$ years, $S D=0.46$ years $)$, participated in the study. Of the 37 children, $75.70 \%$ were Caucasian, $5.40 \%$ were Asian, $2.70 \%$ were African American, and $2.70 \%$ were Hispanic. The children were accompanied by either their mothers (31) or their fathers (6). The average age of the parents was 27.69 years $(S D=4.20$ years) and the average amount of education was 14.11 years $(S D=2.93$ years $)$ for the parent and $15.48(S D=2.76$ years) for the parent's spouse. Average family income ranged as follows: $21.60 \%$ made between 
$\$ 0$ and $\$ 10,000.00,13.50 \%$ made between $\$ 10,000.00$ and $\$ 15,000.00,24.30 \%$ made between $\$ 15,000.00$ and $\$ 25,000.00,24.30 \%$ made between $\$ 25,000.00$ and $\$ 40,000.00,2.70 \%$ made between $\$ 40,000.00$ and $\$ 60,000.00,2.70 \%$ made between $\$ 60,000.00$ and $\$ 100,000.00$, and $2.70 \%$ made over $\$ 100,000.00$.

\section{Measures}

History Interview Form. The History Interview Form (Appendix A) assesses basic demographic information about the child and family. Parents completed questions about their own and child's date of birth, gender, race, and family's annual income.

State-Trait Anxiety Inventory. The state form of the State-Trait Anxiety Inventory (STAI; Appendix B) was used to assess current parent distress level. This measure consists of 40 selfreport items that assess both current (state) and personality (trait) anxiety levels (Spielberger, 1983). Specifically, there are 20 items that assess the parent's current level of anxiety (state) and 20 items assess the parent's general level of anxiety (trait). When creating the state form, STAIY, of this measure (the one used in this study), over 5,000 subjects were tested. Results indicated that the STAI-Y has good internal consistency with median alpha coefficients of .92 and .90 for the state and trait scales respectively (Spielberger, 1983). Additionally, the STAI has been found to have good concurrent, convergent, divergent, and construct validity. High scores on this measure are indicative of high levels of anxiety.

Parent report. The Parent Post-Procedure Questionnaire (Appendix C) queried parents about their own and their child's distress levels during the immunizations. After the injections, the parent completed post-immunization visual analogue scales (VASs) in response to the following questions: "How distressed were you during your child's shots?" and "How distressed was your child during the shots?" The VASs consisted of $100 \mathrm{~mm}$ horizontal lines with the anchor phrases on each end of the line, (e.g., Not Distressed and Very Distressed). Parents were asked to make a vertical mark along the VAS that corresponded to the point between the two anchors that reflected their response to the question. Because VASs have good validity and reliability and they cause less bunching of scores than categorical scaling methods, they are used widely in distress studies (McGrath, 1990).

Nurse report. In order to gain more information about the parents' and the infants' distress level, nurses completed post-immunization questionnaires (Appendix D). After the injection, the nurses completed VASs in response to the following questions: "How distressed was this parent during this child's shots?" and "How distressed was this child during the shots?"

Observational measures. The Modified Behavior Pain Scale (MBPS; Taddio et al., 1994; Appendix E) was used to assess infant procedural distress. This scale is a revised version of the Children's Hospital of Eastern Ontario Pain Scale (CHEOPS; McGrath et al., 1985) and has good reliability and validity (Taddio et al., 1995). The MBPS protocol specifies that infants be coded along three dimensions: face, cry, and body behavior. Each of the three behaviors is scored independently with a score of 0, 1, 2, or 3 given for 'Facial Expression,' 0, 1, 2, 3, 4 for 'Cry,' and 0, 2, or 3 for 'Body.' For example, a score of 0 on 'Facial expression' would correspond to 'positive expression (smiling), a 1 to 'neutral expression,' a 2 to 'slightly negative 
expression (grimace, brow bulge, naso-labial furrow),' and a 3 to 'definite negative expression (furrowed brow, eyes closed tightly, open lips).'

In order to obtain a more detailed exploration of infant procedural distress, coding was divided into four 10-second phases: baseline (20 seconds prior to injection until 10 seconds prior to injection), pre (10 seconds prior to the injection until the injection), injection (first injection until 10 seconds later), and post (10 seconds after the withdrawal of the last injection until 10 seconds later). Thus, an infant's MBPS score can range from 1 to 10 for each of the 4 phases for a total of 0 to 40 overall. Because I am interested in general distress level over the entire procedure, the overall scores were used during analyses. Phase scores were calculated by adding together each of the scores of the face, cry, and body dimensions for each phase. The overall score was then calculated by summing each of these phase scores.

The Measure of Adult and Infant Soothing and Distress (MAISD; Appendix F) was developed for this study in order to assess parent behavior during infant immunizations. The MAISD coding scheme examines 12 parent behaviors: distraction, offer toy, offer pacifier, offer food, nursing, tickle, rub/pat/massage, kiss, hug, sitting rock, standing rock, and verbal reassurance. These codes were based on reported behaviors exhibited by parents during preschoolers' procedures (e.g., Blount et al., 1989), literature documenting parent behaviors during infants' procedures (Craig et al, 1984), and anecdotal report and observations of parents during infants' immunizations. Coding was divided into three phases: Phase 1 included the three minutes prior to the cleaning of the infant's skin, Phase 2 is the time from cleaning the skin until the last injection is removed, and Phase 3 is the two minutes after the last injection has been removed. Behaviors were coded for either occurrence or non-occurrence during 5-second intervals. Similar to the MBPS, overall scores were used in analyses; the three phases were collapsed to yield one overall score.

Two coders were used for each observational scale; the MBPS and the MAISD. Both sets of coders were trained using data from a prior research experiment. Coding for the present examination began once acceptable interrater reliabilities were obtained (e.g., Kappa scores above 0.60 ). The cut off of 0.60 was based on past research which categorizes Kappas from 0.600.75 as "good" and Kappas above 0.75 as "excellent" (Fleiss, 1981). The coders overlapped on $20 \%$ of the participants and reliability checks were conducted using the Kappa statistic. The coders underwent "brush-up" training if any problems were identified (e.g., the Kappa statistic dropped out of the "good" range). Once the appropriate areas were rectified, coding continued.

Physiological measure. Heart rate has often been used as a measure of anxiety in pediatric procedural studies (for a review, see Sweet \& McGrath, 1998). Thus, parent and infant heart rate was obtained during a baseline phase before the injections, just prior to the injections, immediately after the injections, and approximately 5 to 10 minutes after the injections. To examine heart rate change, the baseline heart rate measure was subtracted from the postimmunization heart rate measure. All heart rate measures were taken using a digital heart rate monitor, the Tanita Cardio ${ }^{\circledR}$, which reportedly is accurate within 5\%. 


\section{Procedure}

Parents with infants between the ages of approximately two months and twenty-four months were approached by a graduate or undergraduate research assistant in the waiting room and asked to participate in the study. If the parent wished to participate, a brief explanation of the purpose of the study was given and consent was obtained. The pulses of the parent and infant were acquired and then the parent completed the History Interview Form and the STAI-State. Upon completion of the forms, the parent and infant were taken to the treatment room. Immediately prior to and following the injections, the nurse obtained parent and infant pulse. The entire procedure was video taped for later behavioral coding. When the parent and infant returned to the waiting room, the parent completed the post-immunization questionnaire and the parent's and infant's delayed pulses were obtained. Additionally, the nurse completed the postimmunization questionnaire.

Results

\section{Reliability Analyses}

Interobserver reliability analyses indicated strong reliability for both the MBPS and MAISD coding schemes. For the MBPS, Cohen's Kappa values fell in the "good" range for each dimension (Fleiss, 1981): 0.64 for cry, 0.64 for body, and 0.68 for face. For the MAISD, Cohen's Kappa values for all of the parent behaviors ranged from 0.82 to 1.00 , which are classified as "excellent."

\section{Preliminary Analyses}

Preliminary analyses were conducted to determine whether any nuisance variables were related to the variables of interest. Specifically, family income level, gender of the child, age of the child, and ethnicity were examined for relations with the following variables: parent distress (i.e., parent self-report, nurse report, STAI-State, heart rate change), parent behavior (i.e., MAISD individual parent behavior codes), and infant distress (i.e., parent report, nurse report, infant heart rate change, MBPS overall score). Pearson product moment correlations were used to assess infant age, whereas analyses of variance (ANOVAs) were used to assess income of family, gender of child, and ethnicity.

No gender differences were found, however, age of the child was negatively correlated with parent walking rock, $r(37)=-.33, p<0.05$. Initially, differences were found among the different ethnic groups for parents' walking rock behavior, $F(3,31)=6.40, p<0.01$ and also parents' offering toys behavior among the levels of family income, $F(6,33)=18.89, p<0.01$. However, given the disparate numbers of participants per cell (e.g., 75.70\% of the sample was Caucasian), Levene's test of homogeneity of variance was examined. Results indicated that in fact the homogeneity of variance assumption had been violated when examining ethnicity and walking rock, $F(3,28)=31.16, p<0.01$, and income and offering toy, $F(6,27)=3.84, p<0.01$; thus, these relations were not considered valid. In sum, only child age was co-varied out of further analyses involving the walking rock behavior. 


\section{Parent and Infant Distress}

Given the limited information about infant and parent procedural distress, descriptive analyses were conducted (see Table 1). The means and standard deviations for infant distress were as follows: parent-report of infant distress $(M=75.77, S D=24.95)$, nurse-report of infant distress $(M=50.08, S D=21.30)$, heart rate change $(M=21.00, S D=29.12)$, and MBPS score $(M=16.46, S D=4.45)$. Additionally, $t$ tests were performed to assess differences between parent and nurse report of infant distress as well as between the various phases of infant heart rate. Results indicated that nurses reported significantly lower infant distress than did parents, $t(35)=4.88, p<0.01$. Also, the mean infant baseline heart rate $(M=113.79, S D=23.25)$ was significantly lower than the mean post-immunization heart rate $(M=134.79, S D=20.25), t(23)$ $=-3.53, p<0.01$. In order to examine the associations among measures of the same construct, each of the infant measures of distress (e.g., MBPS, parent-report) were correlated using Pearson product moment correlations. None of the infant measures of distress were significantly correlated (see Table 2).

Table 1 Means and Standard Deviations for the Measures of Parent and Infant Distress

\begin{tabular}{lll}
\hline Measure & $M$ & $S D$
\end{tabular}

Parent Distress

Self-Report of Distress

Nurse Report of Distress

STAI-State

Heart Rate Change

Infant Distress
56.05

26.47

35.09
26.75

27.69

11.05

20.66

Report of Infant Distress

Nurse Report of Distress

Heart Rate Change 
Table 2

Correlations Among the Measures of Parent and Infant Distress

\begin{tabular}{lcccccccc}
\hline Measure & 1 & 2 & 3 & 4 & 5 & 6 & 7 & 8 \\
\hline 1. Parent Self-Report & -- & & & & & & & \\
2. Nurse Report-Parent & .21 & -- & & & & & & \\
3. Parent Heart Rate & -.14 & .06 & -- & & & & & \\
4. STAI-State & $.57^{* *}$ & .06 & .09 & -- & & & & \\
5. Parent Report-Infant & $.56^{* *}$ & .13 & .01 & .07 & -- & & & \\
6. Nurse Report-Infant & .32 & $.62^{* *}$ & .03 & .05 & .12 & -- & & \\
7. Infant Heart Rate & $-.51^{*}$ & .26 & .03 & -.32 & -.21 & .27 & -- & \\
8. MBPS Total & -.05 & -.21 & .23 & .05 & .14 & -.13 & .24 & -- \\
\hline
\end{tabular}

Note. $* p<.05, * * p<.01$

The mean for each measure of parent distress were as follows: parent self-report $(M=$ $56.05, S D=26.75)$, nurse report $(M=26.47, S D=27.69)$, heart rate change $(M=3.52, S D=$ 20.66), and STAI-State score $(M=35.09, S D=11.05)$. Similar to how parents and nurses rated infant distress, nurses rated parents as being significantly less distressed than how parents rated themselves, $t(35)=5.03, p<0.01$. Additionally, a $t$ test demonstrated that the mean parent baseline heart rate of $78.21(S D=15.47)$ was not statistically different than the mean post immunization heart rate $(M=81.72, S D=15.06), t(28)=-.92, p>0.10$. The various measures of parent distress were correlated using Pearson product moment correlations (see Table 2). Results indicated that parent self-report of distress and the STAI-State scores were significantly correlated, $r(35)=0.57, p<0.01$.

In order to evaluate the relation between parent and infant procedural distress, Pearson product moment correlations were conducted among the parent distress (i.e., parent self-report, nurse report, STAI-State, and heart rate change) and infant distress (i.e., parent report, nurse report, the MBPS, and heart rate change) measures (see Table 2). Significant positive correlations emerged between parent self-report of distress and parent report of infant distress, $r(37)=0.56, p<0.01$, and also nurse report of parent distress and nurse report of infant distress, $r(36)=0.62, p<0.01$. Additionally, parent self-report was significantly negatively correlated with infant heart rate change, $r(24)=-.51, p<0.01$. Finally, the positive correlation between parent self-report and nurse report of infant distress approached significance, $r(36)=0.32, p=$ 0.06 . 


\section{Parent Behavior}

In order to investigate the types of behaviors parents were engaging in during their child's immunization, frequencies were calculated for each behavior. See Table 3 for the mean, standard deviation, minimum, and maximum rate of each parent behavior. The sum of 5-sec intervals in which the parent engaged in a coded behavior was divided by the total number of 5sec intervals that the parent could have engaged in the behavior, resulting in the following average percentages of time spent displaying each behavior: distraction (5.14\%), offer toy $(0.62 \%)$, offer pacifier $(1.02 \%)$, offer food $(0.04 \%)$, nursing $(1.30 \%)$, tickle $(0 \%)$, rubbing $(10.63 \%)$, kissing $(3.00 \%)$, hugging $(2.67 \%)$, sitting rock $(4.23 \%)$, walking rock $(5.32 \%)$, and verbal reassurance $(7.30 \%)$. It should be noted certain infrequent parent behaviors may be highly salient (e.g., giving a child a pacifier only takes a few seconds to do, yet the child may be calmed by the pacifier for some time); thus, even though the rates of many of parent behaviors were very low, most behaviors were used in further analyses. The three behaviors that were excluded from further analyses were tickle, which never occurred, nursing, which was displayed by only one mother, and offer food, which was displayed by only one parent.

Table 3

Means, Standard Deviations, Minimums, and Maximums of the Rates of each Parent Behavior

\begin{tabular}{lcccc}
\hline Parent Behaviors & $M$ & $S D$ & Min & Max \\
\hline Distraction & .05 & .06 & .00 & .28 \\
Offer toy & .006 & .02 & .00 & .09 \\
Offer pacifier & .01 & .02 & .00 & .06 \\
Offer food & .0004 & .003 & .00 & .48 \\
Nurse & .01 & .08 & .00 & .00 \\
Tickle & .00 & .00 & .00 & .57 \\
Rub & .11 & .15 & .00 & .26 \\
Kiss & .03 & .04 & .00 & .29 \\
Hug & .03 & .06 & .00 & .23 \\
Sitting rock & .04 & .06 & .00 & .00 \\
Walking rock & .05 & .00 & .00 & .24 \\
Verbal reassurance & & .00 & .00 \\
\hline
\end{tabular}


To evaluate whether parents' behavior during infants' painful procedures might be categorized in a similar manner as what has been found in the preschooler painful procedure literature (e.g., Blount et al., 1990, 1997), Cronbach's alpha was employed. It was expected that verbal reassurance, hugging, kissing, rubbing, and rocking would be significantly positively correlated, thus forming the 'comforting behavior' group. The 'distracting behavior' group would be developed based on significant positive correlations among distraction, offering a toy, and offering a pacifier. However, these groupings resulted in Cronbach's alphas of less than 0.70 (-.11 for the distracting behaviors and 0.16 for the comforting behaviors). Thus, the parent behaviors were analyzed individually in all further analyses.

\section{Relation Between Parent Behaviors and Infant Distress}

Pearson product moment correlations were conducted to examine the relation among the parent behaviors and the measures of infant distress (see Table 4). Partial correlations were used to partial out the variance accounted for by infant age for the walking rock behavior. The only significant correlation was found between hugging and MBPS score, $r(37)=0.49, p<0.01$. Also, the negative relation between parent distraction and nurse report of infant distress approached significance, $r(36)=-.30, p=0.07$.

Table 4

Correlations among the Parent Behaviors and the Measures of Parent and Infant Distress

\begin{tabular}{|c|c|c|c|c|c|c|c|c|}
\hline \multirow[b]{2}{*}{ Measure } & \multicolumn{4}{|c|}{ Parent Measures } & \multicolumn{4}{|c|}{ Infant Measures } \\
\hline & $\begin{array}{c}\text { Self- } \\
\text { Report }\end{array}$ & $\begin{array}{l}\text { Nurse- } \\
\text { Report }\end{array}$ & $\begin{array}{l}\text { STAI- } \\
\text { State }\end{array}$ & $\begin{array}{l}\text { Heart } \\
\text { Rate }\end{array}$ & $\begin{array}{l}\text { Parent- } \\
\text { Report }\end{array}$ & $\begin{array}{l}\text { Nurse- } \\
\text { Report }\end{array}$ & $\begin{array}{c}\text { MBPS } \\
\text { Total }\end{array}$ & $\begin{array}{l}\text { Heart } \\
\text { Rate }\end{array}$ \\
\hline Distraction & .20 & .04 & .23 & .13 & .07 & -.30 & -.11 & -.34 \\
\hline Offer toy & -.24 & -.21 & -.23 & .05 & .02 & -.26 & .09 & .05 \\
\hline Offer pacifier & -.16 & .22 & $-.35^{*}$ & .18 & .02 & .26 & -.03 & -.15 \\
\hline Rub & -.02 & -.13 & .03 & -.02 & .21 & -.28 & .10 & -.08 \\
\hline Kiss & -.18 & -.13 & .01 & .01 & -.22 & -.18 & -.04 & -.19 \\
\hline Hug & .14 & -.18 & .10 & -.08 & .18 & .09 & $.49 * *$ & -.03 \\
\hline Sitting rock & .003 & $-.39 *$ & .01 & -.06 & .27 & -.22 & .14 & -.20 \\
\hline Walking rock & -.13 & -.11 & -.01 & -.35 & -.08 & -.18 & .03 & .36 \\
\hline $\begin{array}{l}\text { Verbal } \\
\text { reassurance }\end{array}$ & -.14 & .04 & .03 & .13 & .03 & .04 & .09 & .02 \\
\hline
\end{tabular}




\section{Parent Behavior as a Mediator of Parent and Infant and Distress}

To evaluate whether parent behavior mediates the relation between parent distress and infant distress, four conditions are required. First, the predictor, parent distress (A), must be significantly associated with the mediator, parent behavior (B). Second, the predictor, parent distress (A), must be significantly associated with the dependent variable, infant distress (C). Third, the mediator, parent behavior (B), must be significantly associated with the dependent variable, infant distress $(\mathrm{C})$. Lastly, the impact of the predictor, parent distress (A) on the dependent measure, infant distress (C), is less when mediator, parent behavior (B), is controlled for (Baron and Kenny, 1986). As outlined in Holmbeck's (1997) article on this topic, three multiple regression analyses are used to test for mediation. In the first regression, the significance of the $A \rightarrow B$ relation is examined. In the second regression, the $A \rightarrow C$ relation is examined. Finally, in the third regression, $\mathrm{A}$ and $\mathrm{B}$ are used as predictors with $\mathrm{C}$ as the dependent variable. Here, Baron and Kenny (1986) recommend using simultaneous entry. This third regression tests the significance of both the $\mathrm{B} \rightarrow \mathrm{C}$ and $\mathrm{A} \rightarrow \mathrm{C}$ relations when $\mathrm{B}$ is controlled. Figure 1 illustrates a diagram of this interaction.

\section{(A) Parent Distress}

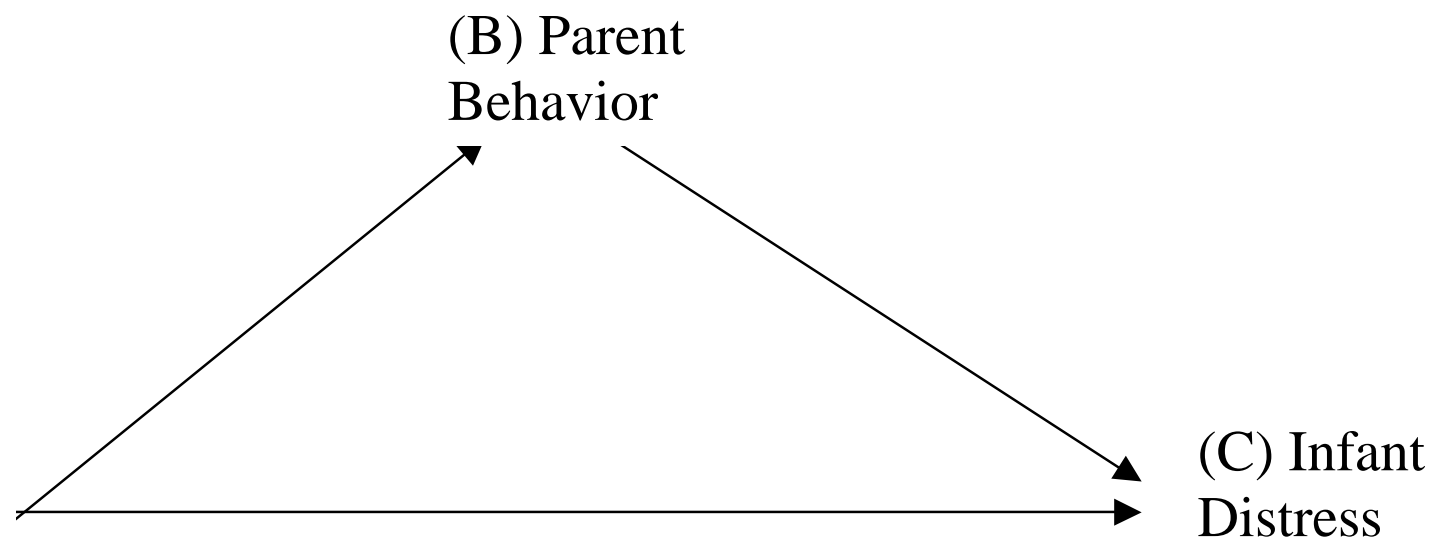

Figure 1. Diagram of the mediating role played by parent behavior in the relations among parent distress, parent behavior, and infant distress.

As a first step, the relation between parent behavior (A) and parent distress (B) was examined using a regression for each of the four measures of parent distress. Since none of the regressions were significant, Pearson product moment correlations were used to examine the relation between the individual parent behaviors and the measures of parent distress (see Table 4). Results indicated that nurse report of parent distress was negatively correlated with parent sitting rock, $r(36)=-.39, p<0.05$. Additionally, parents' STAI-State score was negatively correlated with their offering pacifier, $r(35)=-.35, p<0.05$. Finally, there was a negative association between the walking rock behavior and parent pulse rate change that approached 
significance, $r(29)=-.35, p=0.07$. Thus, there is evidence for a relation between $\mathrm{A}$ and $\mathrm{B}$. Note that the $\mathrm{B} \rightarrow \mathrm{C}$ and $\mathrm{A} \rightarrow \mathrm{C}$ relations were tested in previous analyses.

Although there is some evidence that each of the three relations exists (i.e., parent behavior is related to parent distress, parent distress is related to infant distress, parent behavior is related to infant distress), none of the same variables were consistent across these three relations. Thus, a multiple regression equation to test the possible mediating function of parent behavior was not conducted.

\section{Post-Hoc Power Analyses}

A post hoc power analysis was conducted to determine whether the sample size was sufficient to detect relations among the variables evaluated. With a sample size of 37 subjects, there was $80 \%$ power to detect significant correlations of 0.43 or higher. Given that the correlations ranged from 0.00 to 0.62 , it is likely that power was insufficient to detect a number of potential relations.

\section{Exploratory Analyses}

Exploratory analyses were conducted to further assess infant age and gender differences in infant distress. To assess infant age, infants were divided into two groups: infants younger than twelve months old $(n=23)$ and infants older than twelve months $(n=14) . T$ tests were then conducted between these two groups with each of the measures of infant distress (i.e., parentreport, nurse-report, MBPS score, and heart rate change). No significant differences were found. Infant gender was assessed in the same manner, and no significant differences were found.

Additional exploratory analyses were conducted in order to examine possible differences among infant age and infant procedural distress by phase of the procedure. (For means and standard deviations for the MBPS and MAISD by phase, see Table 5.) Pearson product moment correlations were calculated for infant age and each phase of the MBPS (i.e. baseline, preimmunization, immunization, and post-immunization). There were no significant correlations found. Gender was evaluated with $t$ tests to evaluate whether male or females exhibited different amounts of distress at the different phases of the MBPS. No significant differences emerged.

To further examine the relation between parent behavior and infant distress, the procedure was evaluated by phases. This was accomplished by conducting Pearson product moment correlations between the phases of the MAISD and the corresponding phases of the MBPS. Since the MAISD has only three phases (i.e., baseline, immunization, and postimmunization), the four MBPS phases were adjusted to match the MAISD phases. Specifically, the baseline and pre-immunization phases of the MBPS were collapsed so that it would correspond to the first phase of the MAISD. Parents' distraction was found to be inversely related to infants' MBPS score during the immunization phase, $r(37)=-.34, p<0.05$. 
Table 5

Means and Standard Deviations for MBPS and MAISD by Phase

Baseline Immunization Post-Immunization

Measure and variable

$M$

$S D$

M

$S D$

$M \quad S D$

MBPS

$\begin{array}{lllllll}\text { Total } & 5.08 & 3.03 & 6.59 & 1.46 & 4.78 & 1.89\end{array}$

MAISD

$\begin{array}{lcccccc}\text { Distraction } & .04 & .07 & .04 & .14 & .07 & .14 \\ \text { Offer toy } & .005 & .01 & .00 & .00 & .01 & .04 \\ \text { Offer pacifier } & .006 & .01 & .02 & .07 & .02 & .04 \\ \text { Rub } & .09 & .17 & .20 & .33 & .11 & .17 \\ \text { Kiss } & .02 & .06 & .06 & .14 & .03 & .04 \\ \text { Hug } & .01 & .05 & .02 & .06 & .06 & .15 \\ \text { Sitting rock } & .04 & .08 & .02 & .10 & .06 & .11 \\ \text { Walking rock } & .04 & .16 & 0 & 0 & .09 & .19 \\ \begin{array}{l}\text { Verbal } \\ \text { reassurance }\end{array} & .009 & .03 & .17 & .24 & .13 & .14\end{array}$

\section{Discussion}

The purpose of this study was three-fold: to examine the relation between parent distress and infant distress, to examine the relation between parent behavior and infant distress, and to assess the possible meditating role of parent behavior on the association between parent and infant distress. Despite the lack of consistently strong support for the hypotheses, the results of this study have provided some insights into the relations among parent distress, parent behavior, and infant distress during routine pediatric immunizations.

Preliminary analyses revealed that only child age was correlated with any of the variables of interest. Specifically, child age was inversely related to the walking rock parent behavior. It is logical that as children get older and larger, parents are less likely to choose carrying and rocking as a soothing behavior. This finding highlights the interaction between parents' methods of 
soothing distressed children and children's physical maturation. Clinicians and researchers should be cognizant of patient differences that might impact the choice of distress-management interventions. Additionally, it should be noted that although there were no ethnic differences evident in this sample, there is some evidence that cultural differences in infants' distress responses exists. For example, a recent study demonstrated that Chinese babies exhibited a greater distress response during routine immunizations than non-Chinese babies (Rosmus, Johnston, Chan-Yip, \& Yang, 2000).

The comprehensive examination of infant distress revealed that, in general, different measures of distress did not correlate with each other. This is not entirely surprising given that assessment studies with preschooler procedural distress has frequently found nonexistent or low correlations among measures, which has been interpreted as reflecting the multidimensional nature of distress (e.g., Chambers, Reid, Craig, McGrath, \& Finley, 1998; Jay, 1988; Manne, Jacobsen, Redd, 1992). In addition, the study of assessments of infant procedural distress is relatively new and thus the specificity of some of the measures is still being assessed. For example, there is no known research assessing correlates of either parents' or nurses' estimates of infant distress. Further, although the MBPS has proven to be sensitive to changes in infant distress behavior through correlations with trained observers' and pediatrician's VAS scores, similar analyses have not been conducted with parents' or nurses' ratings. It is also possible that parents and nurses are attending to different infant behaviors when measuring infant distress. For example, a nurse would likely use other infants as a baseline with which to compare the target infant's distress, and a parent would likely use his/her own child's typical behavior with which to compare the current distress behavior. Moreover, although heart rate has been shown to reliably assess infant pain, it is not necessarily pain specific (Sweet \& McGrath, 1998). In fact, Sweet and McGrath (p. 78) highly recommend measuring distress in a multidimensional fashion and not relying entirely on any one measure as the sole indicator of distress.

Like the infant measures of distress, most of the parent measures of distress did not intercorrelate. In fact, only parent self-report and STAI-State scores were positively associated, suggesting that parents are consistent in their reports of their own distress during their infant's immunization. Since researchers have found that parents are good at masking overt indicators of distress (Boyer \& Barakat, 1996), it is not remarkable that nurse report of parent distress was much lower than, and did not correlate with, parent self-report of distress. Further, it is difficult to interpret parent heart rate change in this situation. Although parent heart range changed negligibly, it is possible that parents already were aroused, maybe because they anticipated how the injection would upset their infant. Thus, they might have simply remained aroused throughout the medical visit. It is important to note that distress is an internal and multidimensional experience. Thus, parent report could be an accurate perception of the parents' own internal experiences, nurse report might accurately assess the parents' overt distress behaviors, and heart rate change might accurately measure physiological distress. Moreover, nurses likely compare target parents to a baseline of other parents, whereas parents might evaluate their own distress compared to their usual distress. Future studies might more closely examine these participant rating measures and how they should be interpreted. Additionally, it would be useful to examine more subtle overt parent distress behaviors that may have been overlooked in the past that could be helpful in assessing parent distress behavior. For example, distressed parents may have a more rigid body posture. Regardless, researchers and clinicians 
should appreciate that parents are reporting and being rated as experiencing moderate to high levels of distress, and that multiple measures are necessary in order to gain a comprehensive evaluation of parent distress during their child's painful procedure.

In the examination across infant and parent distress, several measures were significantly related. First, parent self-report of distress and parent report of infant distress were significantly positively correlated, and nurse report of parent distress and nurse report of infant distress were positively associated. Also the positive relation of parent self-report and nurse report of infant distress approached significance. These results support the hypothesis of a positive association between parents' and their infants' procedural distress. Moreover, both parents and nurses are reporting high levels of consistent distress between parents and infants. Given the correlational nature of these results, only speculative causal relations can be delineated. Specifically, these results might reflect parents' distress reaction to their infants' distress, infants' distress reactions to their parents' distress, and/or a genetic/environmental association across both infants and parents. Additionally, method variance should not be ignored, in that similarities might reflect the raters' biases. For example, a nurse might assign a high rating to a visibly distressed infant and then give the parent a similarly high rating regardless of the parents' overt distress behavior. In sum, there is evidence to suggest a positive relation between parent and infant distress during pediatric procedures, which parallels the literature with preschoolers (e.g., Jay et al., 1983). Thus, when attempting to soothe a distressed infant, clinicians should attend to the parents' distress too.

Interestingly, parent self-report of distress was found to be negatively correlated with infant heart rate change. However, given the above mentioned problem of using heart rate alone as a sole indicator of infant distress combined with the fact that infant heart rate did not correlate with MBPS scores, heart rate might not have been a good indicant of infant distress in the current study. Thus, this finding should be interpreted cautiously. It also is possible that parents who have high distress have infants who already have high heart rates at baseline that continue to remain high after the immunization. Future studies could tease this apart to clarify the relation between infant physiological distress response and parent self-report of distress.

Along with parent distress, parent behavior was examined to determine how it relates to infant distress. First, it should be noted that parents were exhibiting very low rates of the behaviors assessed. In fact, few of the behaviors occurred more than 5\% of the time. It might be that parents do not know the best way to respond to their distressed infant during a medical procedure. Cohen, Manimala, and Blount (2000) found similar results in their examination of preschoolers undergoing routine immunizations; with parent behaviors ranging from occurring $0 \%$ to $10 \%$ of the time, and most behaviors occurring less that $5 \%$ of the time. Even though parents are exhibiting minimal behavior, parent behavior should not be ignored. Quite the contrary, as it is possible that some low frequency parent behaviors are critical in exacerbating or diminishing infant distress. For example, one instance of giving an infant a toy might calm the child for a substantial period of time. Further, ignoring the child when he or she is distressed might upset a child more than the needle injection itself. Thus, it is necessary to determine what role parent behaviors play in infant distress so that parents might learn to recognize and engage in those behaviors that are most helpful to their distressed infant and also decrease those behaviors that might prompt or exacerbate infant distress. 
Although parent behavior might be low in frequency, previous studies (Blount et al., $1990,1997)$ with preschoolers has shown that parent behavior can be grouped into 'distracting behaviors' (which are associated with lower preschooler distress) and 'comforting behaviors' (which are associated with higher preschooler distress). Although it was expected that the parent behaviors in this study would group in a similar manner, this was not the case. This supports the notion that parents employ different behaviors with infants than with preschoolers or older children. Of the parent behaviors, only hugging was positively correlated with infant distress. This finding makes intuitive sense because it would be expected that infants who are more distressed would be more likely to have their parents hug them than infants who are less distressed. It might also be that hugging increases or prolongs the child's distress. Due to the correlational nature of this study, this question cannot be answered here; however, it is worthy of further investigation. In fact, it is highly recommended that further research be conducted to determine the effects of other parent behaviors on infant distress so that effective treatments and recommendations might be developed.

The results also might be interpreted as suggesting that, unlike the findings with preschoolers and older children, parent behavior has little influence on infants' distress reaction to an acute painful stimulus. In fact, this is the conclusion drawn by Lewis and Ramsey (1999). If this were found to be true after sufficient investigation, parents might be both disheartened and relieved. In other words, parents might be disappointed that they are not able to soothe their distressed infant, but feel validated when their efforts are futile. It also might be that infant distress behavior is not as predictable or consistent as preschooler behavior. Related to this, given that infants cannot verbalize their distress, it is more difficult for researchers to quantify infant distress with the current assessment tools. As our measurement instruments of infant distress and parent behavior become more precise, we might gain additional insights in this relation or lack there of.

Just as parent behavior was expected to be related to infant distress, it was expected that there would be a relation between parent distress and parent behavior. Some evidence for this claim was found. First, parents who were seen as more distressed were less likely to rock their infant than parents who were seen as less distressed. Second, parents who were more distressed were less likely to offer their child a pacifier. Finally, the inverse correlation between parent pulse rate change and the walking rock behavior approached significance. Taken as a whole, there are several implications for these three findings. Given that parents' distress was generally related to fewer behaviors, upset parents might be engaging in a 'freeze' reaction. In other words, parents who are distressed simply might refrain from responding. Several researchers have argued that a 'freeze' response, or the relative lack of responding, should be considered a third emergency reaction (aside from the fight or flight reactions) that occurs in response to a stressor (Hamilton, 1989; Jarvik \& Russel, 1979). Another explanation is that parents who do not know how to respond and/or choose to not respond, experience more distress. Due to the correlational nature of these findings, it is not possible to make causal statements and further research is needed to unravel these associations.

Exploratory analyses were conducted in order to further examine the roles played by infant age, gender, and parent behavior in infant distress (overall distress and distress by phase). 
Interestingly, unlike previous studies that have found age related differences in distress levels (e.g., Lilley et al., 1997), results of this study indicated that age of the infant was unrelated to overt distress behavior. However, there was preliminary evidence that parent behavior is differentially related to infant distress behavior across phases of the procedure. It was found that parent use of distraction during the injection phase of the procedure was inversely related with infant distress behavior. This provides support for the common finding in the preschooler literature that parent use of distraction might decrease infant distress. Given that the current finding was correlational, this should be interpreted cautiously.

Limitations of the current study should be noted. First, the sample size was small and a lack of sufficient power might explain some of the null findings. Second, although the homogeneity of the sample increased internal validity, it limits generalization in terms of variables such as age, ethnicity, and medical procedure. Third, even though heart rate change is seen as one of the better physiological indicants of procedural distress, it did not prove especially informative with this sample. Fourth, the behavioral coding scheme, despite being developed on solid theoretical and clinical grounds, might not have captured important parent behaviors. For example, parents might emit subtle behaviors, such as rigid posture, detectable by the infant but not an outside observer. In fact, social referencing, when infants look to their caregivers to see how they should respond in novel situations (e.g., Feinman, 1992), also could have played a role.

Future research is warranted to closely examine these constructs independently and interdependently. In addition, it is important to conduct a more fine-grained evaluation of parent behaviors (e.g., social referencing, distress behavior). Additionally, given that the vast majority of pediatric studies in this area have examined mother-child interactions, it is essential to examine father-child behavior during distressing pediatric procedures. It is possible that fathers behave differently than mothers during their children's procedure, and this information might enlighten and guide treatment suggestions. Moreover, even if fathers behave similarly, their behavior and distress during child procedural distress should not be ignored.

In summary, the current study provided preliminary evidence to suggest that there are positive associations between parent distress and infant distress and also parent behavior and infant distress, and a negative relation between parent distress and parent behavior. These results suggest possible treatment applications. For example, since both parents and infants demonstrated moderate to high levels of distress, it follows that each should be targeted for treatment. One specific implication gleaned from this study is that a possible treatment avenue would be to increase the parent behaviors that are associated with less infant distress. However, it is important to note that more research is needed before definitive treatment recommendations along these lines are made. In fact, even though it was expected that the findings associated with infant distress and the variables related to it would mirror the findings in the preschooler distress literature, the general lack of similar findings could indicate that infant distress is qualitatively different. Further, new theories and measures might have to be created in order to progress in this field. Additionally, some of the discrepant findings (e.g., nurses consistently rated parents as less distressed than parent self-report) have clinical implications. For example, nurses may need to be trained as to which behaviors are indicative of parent distress or to query parents about their distress levels, lest nurses incorrectly assume that parents are not experiencing distress. Overall, this study has provided some provocative results and further research based on these findings can 
increase our understanding of infant distress, parent distress, and parent behavior during routine immunizations. 


\section{References}

Anand, K. J. (1990). The biology of pain perception in newborn infants. In D. C. Tyler, \& E. J. Krane (Eds. ), Advances in Pain Research Therapy: Vol. 15 (pp. 113-122). New York: Raven Press.

Anand, K. J., \& Craig, K. D. (1996). Editorial: New perspectives on the definition of pain. Pain, 67, 3-6.

Baren, R. M., \& Kenny, D. A. (1986). The moderator-mediator variable distinction in social psychological research: Conceptual, strategic, and statistical considerations. Journal of Personality and Social Psychology, 51, 1173-1182.

Barr, R. G., Young, S. N., Wright, J. H., Cassidy, K., Hendricks, L., Bedard, Y., Yaremko, J., Leduc, D., \& Treherne, S. (1995). "Sucrose analgesia" and diptheria-tetanus pertussis immunizations at 2 and 4 months. Developmental and Behavioral Pediatrics, 16, 220255.

Berenbaum, J., \& Hatcher, J. (1992). Emotional distress of mothers of hospitalized children. Journal of Pediatric Psychology, 17, 359-372.

Blount, R. L. (1987). The dissemination of cost-effective psychosocial programs for children in health care settings. Children's Health Care, 15, 206-213.

Blount, R. L., Bunke, V. L., \& Zaff, J. F. (2000). Bridging the gap between explicative and treatment research: A model and practical implications. Journal of Clinical Psychology in Medical Settings, 7, 79-90.

Blount, R. L., Cohen, L. L., Frank, N. C., Bachanas, P. J., Smith, A. J., \& Manimala, M. R. \& Pate, J. T. (1997). The child-adult medical procedure interaction scale-revised: An assessment of validity. Journal of Pediatric Psychology, 22, 73-88.

Blount, R. L., Corbin, S. M., Sturges, J. W., Wolfe, V. V., Prater, J. M., \& James, L. D. (1989). The relationship between adults' behavior and child coping and distress during BMA/LP procedures: A sequential analysis. Behavior Therapy, 20, 585-601.

Blount, R. L., Landolf-Fritsche, B., Powers, S. W., \& Sturges, J. W. (1991). Differences between high and low coping children and between parent and staff behaviors during painful medical procedures. Journal of Pediatric Psychology, 16, 795-809.

Blount, R. L., Sturges, S. W., \& Powers, S. W. (1990). Analysis of child and adult behavioral variations by phase of medical procedure. Behavior Therapy, 21, 33-48.

Boyer, B. A., \& Barakat, L. P. (1996). Mothers of children with leukemia: Self-reported and observed distress and coping during painful pediatric procedures. The American Journal of Family Therapy, 24, 227-241. 
Bush, J. P., \& Cockrell, C. S. (1987). Maternal factors predicting parenting behaviors in the pediatric clinic. Journal of Pediatric Psychology, 12, 505-518.

Bush, J. P., Melamed, B. G., Sheras, P. L., \& Greenbaum, P. E. (1986). Mother-child patterns of coping with anticipatory medical stress. Health Psychology, 5, 137-157.

Campbell, L. A., Kirkpatrick, S. E., Berry, C. C., Penn, N. E., Waldman, J. D., \& Mathewson, J. W. (1992). Psychological preparation of mothers of preschool children undergoing cardiac catheterization. Psychology and Health, 7, 175-185.

Campos, R. G. (1989). Soothing pain-elicited distress in infants with swaddling and pacifiers. Child Development, 60, 781-792.

Campos, R. G. (1994). Rocking and pacifiers: Two comforting interventions for heelstick pain. Research in Nursing and Health, 17, 321-331.

Cella, D. F., Perry, S. W., Poag, M. E., Amand, R., \& Goodwin, C. (1988). Depression and stress response in parents of burned children. Journal of Pediatric Psychology, 13, 87-99.

Chambers, C. T., Reid, G. J., Craig, K. D., McGrath, P. J., \& Finley, G. A. (1998). Agreement between child and parent report of pain. Clinical Journal of Pain, 14, 336-342.

Cohen, L. L., Blount, R. L., \& Panopoulos, G. (1997). Nurse coaching and cartoon distraction: An effective and practical intervention to reduce child, parent, and nurse distress during immunizations. Journal of Pediatric Psychology, 22, 355-370.

Cohen, L. L., Manimala, M. R., \& Blount, R. L. (2000). Easier said than done: What parents say they do and what they do during children's immunizations. Children's Health Care, 29, 79-86.

Craig, K. D., McMahon, R. J., Morison, J. D., \& Zaskow C. (1984). Developmental changes in the infant pain expression during immunization injections. Social Science and Medicine, 19, 1331-1337.

Craig, K. D., Whitfield, M. F., Grunau, R. V., Linton, J., \& Hadjistavropoulos, H. D. (1993). Pain in the preterm neonate: behavioural and physiological indices. Pain, 52, 287-299.

Derbyshire, S. W. (1999). Locating the beginnings of pain. Bioethics, 13, 1-31.

Feinman, S. (1992). Social Referencing and the Social Construction of Reality in Infancy. New York: Plenum Press.

Finley, G. A., \& McGrath, P. J. (Eds.). (1998). Measurement of pain in infants and children: Vol.10. Progress in pain research and management. Seattle: IASP Press. 
Fleiss, J. L. (1981). Balanced incomplete block designs for inter-rater reliability studies. Applied Psychological Measurement, 5, 105-112.

Frank, N. C., Blount, R. L., Smith, A. J., Manimala, M. R., Martin, J. K. (1995). Parent and staff behavior, previous child medical experience, and maternal anxiety as they relate to child procedural distress and coping. Journal of Pediatric Psychology, 20, 277-289.

Gray, L., Watt, L., \& Blass, E. M. (2000). Skin-to-skin contact is analgesic in healthy newborns. Pediatrics, 105, 1-6.

Grunau, R. V., \& Craig, K. D. (1987). Pain expression in neonates: Facial action and cry. Pain, $28,395-410$.

Grunau, R. V., Johnston C. C., \& Craig, K. D. (1990). Neonateal facial and cry responses to invasive and non-invasive procedures. Pain, 42, 295-305.

Gunnar, M. R., Porter, F. L., Wolf, C. M., Rigatuso, J., \& Larson, M. C. (1995). Neonatal stress reactivity: Predictions to later emotional temperament. Child Development, 66,_1-13.

Hallstrom, B. J. (1968). Contact comfort: Its application to immunization injections. Nursing Research, 17, 130-134.

Halperin, S. A., McGrath, P., Smith, B., \& Houston, T. (2000). Lidocaine-prilicaine patch decreases the pain associated with the subcutaneous administration of measles-mumpsrubella vaccine but does not adversely affect the antibody response. Journal of Pediatrics, 136, 789-794.

Hamilton, L. (1990). Fight, flight or freeze: Implications of the passive fear response for anxiety and depression. Phobia Practice and Research Journal, 2, 17-27.

Hatch, D. J. (1987). Analgesia in the neonate. British Medical Journal, 294, 920.

Herschel, M., Khoshnood, B., Ellman, C., Maydew, N., \& Mittendorf, R. (1998). Neonatal circumcision: Randomized trial of a sucrose pacifier for pain control. Archive of Pediatric and Adolescent Medicine, 152,_279-284.

Holmbeck, G. N. (1997). Toward terminological, conceptual, and statistical clarity in the study of mediators and moderators: Examples from the child-clinical and pediatric psychology literatures. Journal of Consulting and Clinical Psychology, 65, 599-610.

Izard, C. E., Hembree, E. A., Dougherty, L. M., \& Spizzirri, C. C. (1983). Changes in facial expressions of 2- to 19- month-old infants following acute pain. Developmental Psychology, 3, 418-426. 
Jacobsen, P. B., Manne, S. L., Gorfinkle, K., Schorr, O., Rapkin, B., \& Redd, W. H. (1990). Analysis of child and parent behavior during painful medical procedures. Health Psychology, 9, 559-576.

Jarvik, L. F., \& Russel, D. (1979). Anxiety, aging, and the third emergency reaction. Journal of Gerontology, 34(2), 197-200.

Jay, S. M. (1988). Invasive medical procedures: psychological intervention and assessment. In: Routh D. K., ed. Handbook of pediatric psychology. New York, NY: Guilford; 1988:40125.

Jay, S. M., \& Elliott, C. H. (1990). A stress inoculation program for parents whose children are undergoing painful medical procedures. Journal of Consulting and Clinical Psychology, $58,799-804$.

Jay, S. M., Ozolins, M., Elliot, C. H., \& Caldwell, S. (1983). Assessment of children's distress during painful medical procedures. Health Psychology, 2, 133-147.

Johnston, C. C., \& Strada, M. E. (1986). Acute pain response in infants: a multidimensional description. Pain, 24, 373-382.

Johnston, C. C., Stremler, R. L., Stevens, B. J., \& Horton, L. J. (1997). Effectiveness of oral sucrose and simulated rocking on pain response in preterm neonates. Pain, 72, 193-199.

Kaplan, D. M., Smith, A., Grobstein, R., \& Fischman, S. E. (1973). Family mediation of stress. Social Work, 18, 60-69.

Kazak, A. E., \& Barakat, L. P. (1997). Brief Report: Parenting stress and quality of life during treatment for childhood leukemia predicts child and parent adjustment after treatment ends. Journal of Pediatric Psychology, 22, 749-758.

Korner, A. F., \& Thoman, E. B. (1972). The relative efficacy of contact and vestibularproprioceptive stimulation in soothing neonates. Child Development, 43, 443-453.

LaMontagne, L., Hepworth, J. T., Byington, K. C., \& Chang, C. Y. (1997). Child and parent emotional responses during hospitalization for orthopedic surgery. More about the emotional contagion between parental anxiety and their child's anxiety. American Journal of Maternal/Child Nursing, 22, 299-303.

Lewindon, P. J., Harkness, L., \& Lewindon, N. (1998). Randomized controlled trial of sucrose by mouth for the relief of infant crying after immunization. Archive of Disease of Children, 78, 453-456.

Lewis, M., \& Ramsay, D. S. (1999). Effect of maternal soothing on infant stress response. Child Development, 70, 11-20. 
Lilly, C. M., Craig, K. D., \& Grunau, R. E. (1997). The expression of pain in infants and toddlers: developmental changes in facial action. Pain, 72, 161-170.

Manne, S. L., Bakeman, R., Jacobsen, P., \& Redd, W. H. (1993). Children's coping during invasive medical procedures. Behavior Therapy, 24, 143-158.

Manne, S. L., Jacobsen, P. B., \& Redd, W. H. (1992). Assessment of acute pediatric pain: Do child self-report, parent ratings, and nurse ratings measure the same phenomenon? Pain, $48,45-52$.

Manne. S. L., Redd, W. H., Jacobsen, P. B., Gorfinkle, K. Schorr, O., \& Rapkin, B. (1990). Behavioral intervention to reduce child and parent distress during venipuncture. Journal of Consulting and Clinical Psychology, 58, 565-572.

Martinson, I. M., Liu-Chiang, C., Yi-Hua, L. (1997). Distress symptoms and support systems of Chinese parents of children with cancer. Cancer Nursing, 20, 94-97.

Maxwell, L. G., Yaster, M., Wetzel, R. C., \& Niebyl, J. R. (1987). Penile nerve block for newborn circumcision. Obstetrician and Gynecology, 70, 415-419.

McGrath, P. J., (1990). Pain in children: Nature, assessment, and treatment. New York: Guilford.

McGrath, P. J. (1998). Behavioral measures of pain. In G. A. Finley \& P. J. McGrath (Eds.), Measurement of pain in infants and children: Vol.10. Progress in pain research and management (pp. 83-102). Seattle: IASP Press.

McGrath, P. J., Johnson, G., Goodman, J. T., Schillinger, J., Dunn, J., \& Chapman, J. A. (1985). CHEOPS: A behavioral scale for rating postoperative pain in children. In H. L. Field, R. Dubner, \& F. Cervero (Eds.), Advances in pain research and therapy: Vol. 9. Proceedings of the fourth world congress on pain (pp. 395-402). New York: Raven Press.

McIntosh, N., van Veen, L., \& Brameyer, H. (1994). Alleviation of the pain of heel prick in preterm infants. Archives of Disease in Children, 70,_177-181.

Melnyk, B. M. (1994). Coping with unplanned childhood hospitalization: Effects of informational interventions on mothers and children. Nursing Research, 43, 50-55.

Melnyk, B. M. (1995). Parental coping with childhood hospitalization: A theoretical framework to guide research and clinical interventions. Maternal-Child Nursing Journal, 23, 123131.

Olgivie, L. (1990). Hospitalization of children for surgery: The parent's view. Children's Health Care, 19, 49-56. 
Owens, M. E., \& Todt E. H. (1984). Pain in infancy: neonatal reaction to heel lance. Pain, 20, 77-86.

Peterson, L., \& Shigetomi, C. (1981). The use of coping techniques to minimize anxiety in hospitalized children. Behavior Therapy, 12, 1-14.

Porter, F. L., Grunau, R. E., \& Anand, K. J. (1999). Long-term effects of pain in infants. Developmental and Behavioral Pediatrics, 20, 253-261.

Porter, F. L., Porges, S. W., \& Marshall, R. E. (1988). Newborn cries and vagal tone: parallel changes in response to circumcision. Child Development, 59, 663-669.

Porter, F. L., Wolf, C. M., Gold, J., Lotsoff, D., \& Miller, J.P. (1997). Pain and pain management in newborn infants: A survey of physicians and nurses. Pediatrics, 100, 626-632.

Rosmus, C., Johnston, C. C., Chan-Yip, A., \& Yang, F. (2000). Pain response in Chinese and non-Chinese Canadian infants: Is there a difference? Social Science and Medicine, 51, 175-184.

Rawlings, D. J., Miller, P. A., \& Engel, R. R. (1980). The effect of circumcision on transcutaneous $\mathrm{PO}_{2}$ in term infants. American Journal of Diseases of Children, 134, 676678.

Reis, E. C. (1997). Multiple scheduled infections contribute to missed opportunities to immunize during well care visits. Ambulatory Child Health, 3, 172.

Roberts, M. C., (1992). Vale dictum: An editor's view of the field of pediatric psychology and its journal. Journal of Pediatric Psychology, 11, 785-805.

Ruda, M. A., Ling, Q. D., Hohmann, A. G., Peng, Y. B., \& Tachibana, T. (2000). Altered nociceptive neuronal circuits after neonatal peripheral inflammation. Science, 289, 628630.

Speilberger, C. (1983). Manual for the State-Trait Anxiety Inventory. Palo Alto, CA: Consulting Psychologists Press.

Stevens, B. J., \& Johnston, C. (1994). Physiological responses of premature infants to a painful stimulus. Nursing Research, 43, 226-231.

Stevens, B. J., Johnston, C., \& Grunau, R. V. (1995). Issues of assessment of pain and discomfort in neonates. Journal of Obstetrician and Gynecological Neonatal Nursing, 24, 849-855.

Swafford, L. I., \& Allan, D. (1968). Pain relief in the pediatric patient. Medical Clinics of North America, 52, 131-136. 
Sweet, S. D., \& McGrath, P. J. (1998). Physiological measures of pain. In G. A. Finley \& P. J. McGrath (Eds.), Measurement of pain in infants and children: Vol.10. Progress in pain research and management (pp. 59-81). Seattle: IASP Press.

Sweet, S. D., \& McGrath, P. J. (1998). Relative importance of mothers' versus medical staffs' behavior in the prediction of infant immunization pain behavior. Journal of Pediatric Psychology, 23, 249-256.

Taddio, A. Katz, J., Ilersich, A. L., \& Koren, G. (1997). Effect of neonatal circumcision on pain response during subsequent routine vaccination. Lancet, 439, 599-603.

Taddio, A., Nulman, I., Goldbach, M., \& Ipp, M. (1994). Use of lidocaine-prilocaine cream for vaccination pain in infants. Journal of Pediatrics, 124, 643-648.

Taddio, A., Nulman, I., Koren, B. S., Stevens, B., \& Koren, G. (1995). A revised measure of acute pain in infants. Journal of Pain and Symptom Management, 10, 456-463.

Whelan, T. A., \& Kirkby, R. J. (1997). Parent empowerment: The hospitalization of a child. Journal of Family Studies, 3, 94-107.

Wright, G. Z., Alpern, G. D., Leake, J. L. (1973). The modifiability of maternal anxiety as it relates to children's cooperative dental behavior. Journal of Dentistry for Children, $X L(4), 265-271$.

Zastowny, T. R., Kirschenbaum, D. S., \& Meng, A. L. (1986). Coping skills training for children: Effects on distress before, during, and after hospitalization for surgery. Health Psychology, 5, 231-247.

Zimmermann, R. R., \& Torrey, C. C. (1965). Ontogeny of learning. In A. M. Schrier, H. F. Harlow, \& F. Stollnitz (Eds.). Behavior of Nonhuman Primates: Modern Research Trends (Vol. 2). New York: Academic Press. 


\section{Appendix A: History Interview Form}

\section{History Interview Form}

Date___ Code \#___ Condition___

What is your relation to the child? Your gender? Your race?

Your date of birth?

Your education (highest grade completed/degree)?

Spouse's education (highest grade completed/degree)?

Your occupation?

Spouse's occupation?

Total annual family income?

Circle one of the following: $\$ 0-10,000 \quad 10-15 \quad 15-25 \quad 25-40 \quad 40-60 \quad 60-100 \quad 100+$

What is the gender of this child?___ Child's race?__ Child's date of birth? 


\section{Appendix B: Parent Post-Procedure Questionnaire}

\section{Parent Post-Shot Questionnaire}

Code \# Condition Date

How distressed were you during your child's shots?

Not Distressed Very Distressed

How distressed was your child during the shots?

Not Distressed Very Distressed

Child Delayed Pulse rate. beats in 60 seconds. Taken 2-5 minutes after the injection.

Parent Delayed Pulse rate. beats in 60 seconds. Taken $2-5$ minutes after the injection 


\section{Appendix C: Nurse Post-Procedure Questionnaire}

\section{Nurse Post-Shot Questionnaire}

Code \# Condition Date

How distressed was this parent during this child's shots?

Not Distressed

Very Distressed

How distressed was this child during the shots?

Not Distressed Very Distressed

Child Post-Injection Pulse rate. beats in 60 seconds. Taken immediately following the injection.

Parent Post-Injection Pulse rate. beats in 60 seconds. Taken immediately following the injection. 


\section{Appendix D: Modified Behavior Pain Scale}

MBPS Coder___ Data Set___ Subj\#___ Date on Tape

Baseline $=20$ seconds prior to injection until 10 sec prior to injection (10-sec span). Span

Pre $=10$ secs prior to injection until injection (10-sec span). Span

Injection $=$ Moment of $1^{\text {st }}$ injection until 10 secs later (10-sec span). Span

Post $=$ From 10 secs after withdrawal of last injection until 10 secs later (10-sec span). Span

\begin{tabular}{|l|l|l|l|l|l|l|}
\hline & & & & Slightly negative & $\begin{array}{l}\text { Definite negative } \\
\text { expression (furrowed } \\
\text { brow, eyes closed } \\
\text { tightly, open lips) }\end{array}$ \\
\hline Face & Baseline & Score & $\begin{array}{l}\text { Positive expression } \\
\text { (smiling) }\end{array}$ & Neutral expression & $\begin{array}{l}\text { (grimace, } \\
\text { brow bulge*, naso- } \\
\text { labial furrow*) }\end{array}$ & 3 \\
\hline Face & Pre & 0 & 0 & 1 & 2 & 3 \\
\hline Face & Injection & & 0 & 1 & 2 & 3 \\
\hline Face & Post & & 0 & 1 & 2 & 3 \\
\hline
\end{tabular}

\begin{tabular}{|l|l|l|l|l|l|l|l|}
\hline & & & & & & $\begin{array}{l}\text { Full lunged cry, } \\
\text { more than } \\
\text { baseline or pre } \\
\text { cry (only scored } \\
\text { if infant was } \\
\text { crying at level 3 } \\
\text { during baseline } \\
\text { or pre) }\end{array}$ \\
& Phase & Score & $\begin{array}{l}\text { Laughing or } \\
\text { giggling }\end{array}$ & Not crying & $\begin{array}{l}\text { Mocalizing, } \\
\text { gentle or } \\
\text { whimpering cry }\end{array}$ & $\begin{array}{l}\text { Full lunged cry } \\
\text { or sobbing }\end{array}$ \\
\hline Cry & Baseline & & 0 & 1 & 2 & 3 & 4 \\
\hline Cry & Pre & & 0 & 1 & 2 & 3 & 4 \\
\hline Cry & Injection & & 0 & 1 & 2 & 3 & 4 \\
\hline Cry & Post & & 0 & 1 & 2 & 3 & 4 \\
\hline
\end{tabular}

\begin{tabular}{|l|l|l|l|l|l|}
\hline & & & $\begin{array}{l}\text { Partial movement or attempt } \\
\text { to avoid pain by withdrawing } \\
\text { the limb where puncture is } \\
\text { done (squirming, arching, } \\
\text { limb tensing/clenching) }\end{array}$ & $\begin{array}{l}\text { Agitation with complex } \\
\text { movements involving the } \\
\text { head, torso, or other limbs, or } \\
\text { rigidity }\end{array}$ \\
\hline Body & Baseling / & Score & Relaxed & 2 & 3 \\
\hline Body & Pre & 0 & 0 & 2 & 3 \\
\hline Body & Injection & & 0 & 2 & 3 \\
\hline Body & Post & & 0 & 2 & 3 \\
\hline
\end{tabular}

Total Baseline Score (sum baseline Face, Cry, and Body scores across Phases) =

Total Pre Score (sum pre Face, Cry, and Body scores across Phases) =

Total Injection Score (sum injection Face, Cry, and Body scores across Phases) =

Total Post Score (sum post Face, Cry, and Body scores across Phases) =

Total number of shots received $=$

Total number of shots received during Injection Phase $=$

*Brow bulge is the bulging, creasing, and vertical furrow above and between the brows occurring as a result of the lowering and drawing together of the eyebrows. Naso-labial furrow is the line/wrinkle that begins adjacent to the edges of the nostrils and runs down and outward beyond the edges of the mouth. 
Appendix E: Measure of Adult and Infant Soothing and Distress

Measure of Adult and Infant Soothing and Distress (MAISD)

Coding Manual

1. Make sure that you are calm and focused. If you feel foggy or rushed, do not attempt to code. Bad coding is worse than no coding. We will be doing reliability checks (recoding) on a randomly selected $20 \%$ of subjects and if coding is not reliable, we will have to recode everything. Read this entire manual before beginning coding.

2. Get the Infant, Parent, and Nurse Behaviors Coding Sheets and big videotape.

3. Write the Subject number, your initials, the date (from the recording), and the number of people being coded on the top of the sheets.

4. Cue the tape until you find where the nurse begins cleaning the child's skin for the injection. Write this time down on a scrap piece of paper because you will need it later.

5. Rewind the tape exactly 3 minutes from the beginning of the cleaning. That will be where you being coding. Round down to the nearest 5 seconds (e.g., If the time is 8:45:38, rewind to 8:45:35).

6. Write this time down on the first available spot on the Coding Sheets. In other words, if the time that you will start (i.e., 3 minutes prior to cleaning) is 8:45:35, then fill in $8: 45$ to the left of ':35' on the Coding Sheets. You do not need to put 8:45 next to the following numbers, but do put the next minute down (i.e., 8:46 next to the ':00'). Cross through the blank part of the page above

7. From the beginning of coding until the cleaning of the child's skin is Phase 1 (remember I said in point 3 above to write the time down). Indicate this on the far left of the page by putting a 1 at the beginning time (i.e., 3 minutes prior to cleaning) and the ending time (i.e., cleaning of the skin).

8. Now you are set to begin coding. Focus on one participant at a time. In other words, if you want to code the child first, only code the child. Do not attempt to code the child, parent, and nurse simultaneously.

9. Watch the child's behavior, the running clock, and where you are on your page. This takes some practice and you will have to rewind several time when you first start coding.

10. Each time the child exhibits one of the coded behaviors, put a 1 on the sheet in the box corresponding to that code and the time interval (if it occurred at 9:15:28 it would go in the 9:15:25 box).

11. If a behavior continues for more than 5 seconds, continue to code it for each interval that 
it occurs.

12. If you are unable to see the child, parent, or nurse, put a 1 in the Not Visible box on the correct sheet. If you are able to hear the child, parent, or nurse (e.g., crying, distracting comments, kiss), continue to code these behaviors. If you are able to make a good guess at the non-visible behavior (e.g., if the child is smiling before someone blocks the view of the child's face and the child is still smiling after the blocker is gone), code this too.

13. When the nurse removes the needle from the child for the last injection (this may include $1,2,3$, or more injections), this indicates the end of Phase 2. Round up to the next 5second block. Put a 2 to the left of that box and a 2 in the box following the indication of the end of Phase 1.

14. When the nurse withdraws the needle for the final injection, note that time on a scrap of paper. You will only code for 2 more minutes after that point or else until the child leaves the room, whichever comes first. This segment is Phase 3.

15. Once you have finished coding the child, transfer your time and phase indications to the parent and nurse sheets.

16. Now rewind the tape and code the parent and nurse behaviors.

17. When finished, indicate this on the signup sheets and put the coding sheets into the proper basket.

18. Relax and give yourself a pat on the back for a job well done.

Phases

1. Up to 3 minutes prior to the application of the alcohol or cleaning the infant's skin for the first injection.

2. From the cleaning of the skin for the first injection until the withdrawal of the needle for the final injection (this may include 1, 2, 3, or more injections).

3. From the withdrawal of the last injection until 2 minutes pass, the infant leaves the room, or taping ends, whichever comes first. 
MAISD Coding Manual

\begin{tabular}{|c|c|}
\hline Adult Category & Definition and Examples \\
\hline Distraction & $\begin{array}{l}\text { Behaviors intended to distract the infant. This may include the use of props (e.g., holding up } \\
\text { toys, pointing to posters on the wall) or not (e.g., making funny faces, clapping). This is still } \\
\text { coded even if the child does not appear to be distracted by the behavior. }\end{array}$ \\
\hline Offer Toy & $\begin{array}{l}\text { If the adult simply hands the child a toy-like object in an effort to comfort or distract } \\
\text { him/her. If the parent uses the toy to interact with the child, code Distraction and not Offer } \\
\text { Toy. Often an adult may hand the child a toy so that the child will soothe him/herself. }\end{array}$ \\
\hline Offer Pacifier & $\begin{array}{l}\text { If the parent either hands the infant the pacifier or puts the pacifier in the infant's mouth. } \\
\text { This is still coded if the infant does not accept the pacifier. }\end{array}$ \\
\hline Offer Food & $\begin{array}{l}\text { Feeding can include handing the child a bottle, cracker, or other food. Code even if the child } \\
\text { rejects the food. Do not code this if the mother attempts to or is nursing the child. }\end{array}$ \\
\hline Nursing & Attempts to nurse or actually engaging in nursing. \\
\hline Tickle & $\begin{array}{l}\text { Purposeful tickling of the child in order to produce laughter. The child does not have to } \\
\text { laugh or squirm. }\end{array}$ \\
\hline Rub/Massage/Pat & $\begin{array}{l}\text { Rubbing, massaging, or patting the child. This may be on the head, back, or other body part. } \\
\text { This is often intended to distract and/or comfort the child. }\end{array}$ \\
\hline Kiss & Kissing the child. \\
\hline Hug & $\begin{array}{l}\text { A comforting hug. If the adult is simply holding the child so that the procedure may be } \\
\text { performed, do not code hug. This has to be an obvious and blatant squeeze. }\end{array}$ \\
\hline Sitting Rock & $\begin{array}{l}\text { If the parent remains in the chair and begins to sway, rock, or bounce the child. Code } \\
\text { Standing Rock if the parent stands up and/or walks. }\end{array}$ \\
\hline Standing Rock & $\begin{array}{l}\text { When the adult stands up and rocks, sways, or bounces, or when the adult moves around the } \\
\text { room while holding the child. }\end{array}$ \\
\hline Happy Behavior & $\begin{array}{l}\text { If the adult is displaying either non-verbal (e.g., smiling) or verbal behavior (e.g., "you did } \\
\text { such a good job!") to indicate happiness or positive mood. }\end{array}$ \\
\hline Sad Behavior & $\begin{array}{l}\text { The adult engages in either non-verbal (e.g., sad expression) or verbal (e.g., "I'm sorry") } \\
\text { behavior that indicates feelings of sadness. }\end{array}$ \\
\hline $\begin{array}{l}\text { Angry/Disappointed } \\
\text { Behavior }\end{array}$ & $\begin{array}{l}\text { Non-verbal (e.g., frown) or verbal (e.g., "You are being bad") behavior that indicates } \\
\text { feelings of anger or disappointment in the child or situation. }\end{array}$ \\
\hline Pain Behavior & $\begin{array}{l}\text { Non-verbal (e.g., grimace) or verbal (e.g., "ouch") behavior that implies or models pain } \\
\text { behavior. }\end{array}$ \\
\hline Verbal Reassurance & Reassuring comments (e.g., "it is okay" "we are almost done" "it's alright, baby"). \\
\hline Not Visible & $\begin{array}{l}\text { Code if the adult is not visible. You may still be able to code things that you can hear (e.g., } \\
\text { Verbal Reassurance) and if you have a good guess at a behavior. For example, if the adult is } \\
\text { frowning, then turns his/her back to the camera, and then turns around again and is still } \\
\text { frowning, you can guess that he/she continued to frown when not visible. }\end{array}$ \\
\hline
\end{tabular}




\section{REBECCA SUZANNE BERNARD}

Curriculum Vitae

Work Address:

Home Address:

E-mail Address:

Telephone:

Date of Birth:
Department of Psychology

West Virginia University

Morgantown, WV 26505

475 Wilson Ave.

Morgantown, WV 26505

rebesoccer@aol.com

Work: (304) 293-2001 ext. 834

Home: (304) 292-5002

August 15, 1977

\section{Graduate:}

\section{EDUCATION AND TRAINING}

Clinical Psychology Doctoral student, West Virginia University, Morgantown, West Virginia (8/00 - present)

Clinical Psychology Doctoral student, Washington State University, Pullman, Washington $(8 / 99-7 / 00)$

\section{Undergraduate:}

B.S., Psychology, Summa Cum Laude, University of California, San Diego, La Jolla, California (3/99)

Honor Societies: Phi Beta Kappa (1999-present); Golden Key Honors Society (1998-present); Psi Chi Psychology Honors Society (1998-present)

\section{HONORS AND AWARDS}

HERF Award, West Virginia University (2000-2001)

Graduate School Scholar Award, Washington State University (1999-2000)

Award for Excellence in Scholarship, University of California, San Diego (1999) 
Outstanding Scholastic Achievement, University of California, San Diego (1999)

Provost's Honor Roll, 11 quarters, University of California, San Diego (1995-1999)

Alpha Chi Omega Book Scholarship (1999)

\section{PROFESSIONAL AFFILIATIONS}

Association for Advancement of Behavioral Therapy (10/00-present)

Society of Pediatric Psychology (4/01 - present)

\section{RESEARCH EXPERIENCE}

Graduate Research Assistant, CHAMP Lab (8/00-present)

This lab conducts a variety of studies examining various aspects of pediatric medical procedures. Duties include helping formulate studies, coordinating research assistants, supervising data management and coding, and data analysis. Supervisor: Dr. Lindsey Cohen

Graduate Research Assistant, "A Critical Time to Intervene: A Longitudinal Study of Infant's Fear, Anxiety, and Pain During Immunizations." (8/99-8/00)

Study of infant pain and distress during immunization procedures. Duties included coordinating research assistants, obtaining physiological measures of infant and parent distress, applying topical anesthesia (EMLA), supervising data management and coding. Supervisor: Dr. Lindsey Cohen.

Undergraduate Research Assistant, (3/98-6/99)

Study of the function of echolaic speech in children with autism. Duties included assisting with functional analog assessments, coding, and assisting in the administration of standardized assessments. Supervisors: Dr. Laura Schreibman and Michelle Sullivan

Undergraduate Research Assistant, (9/97-6/99)

A three-year longitudinal treatment study looking at a comprehensive approach (e.g., medical treatment, psychological services, etc.) to treating patients with both psychiatric and substance abuse problems. Duties included co-leading a socialization group, giving standardized assessments, data entry, and participation in client case evaluations. Supervisor: Dr. Nancy Thomas

\section{Undergraduate Research Assistant, (9/97-6/98)}

Study that examined the neuropsychology of thought disorders among geriatric patients with schizophrenia. Duties included coding of auditory tapes of schizophrenic patients and helping obtain the articles necessary for the research. Supervisor: Dr. William Perry 
Undergraduate Research Assistant, (9/97-12/97)

Study that investigated the effects of a 'worried' confederate on participants (emotional contagion). Duties included acting as the confederate. Supervisors: Dr. James Kulik and Christine Harris

\section{PUBLICATIONS}

Cohen, L. L., Blount, R. L., Cohen, R. J., McClellan, C. B., Bernard, R. S., \& Ball, C. M. (2001). Children's expectations and memories of acute distress: The short- and long-term efficacy of pain management interventions. Journal of Pediatric Psychology, 26, 367374.

McNeil, C. B, Filcheck, H. A., Greco, L. A., Ware, L. M, Bernard, R. S. (2001) ParentChild Interaction Therapy: Can a Manualized Treatment Be Functional? Behavior Analyst Today, 2, 106-114.

\section{MANUSCRIPTS UNDER REVIEW}

Cohen, L. L., Bernard, R. S., Greco, L. A., McClellan, C. B. Child Coping Skills, Parent Coaching, and Nurse Coaching: Getting Specific about How to Reduce Pediatric Procedural Distress. Journal of Pediatric Psychology.

\section{POSTER PRESENTATIONS}

Cohen, L. L., Bernard, R.B., \& McClellan, C.B. (November 2001). Pediatric procedural approach-avoidance coping and distress: A multitrait-multimethod assessment. Poster presented at the AABT Convention, Philadelphia.

Cohen, L. L., Bernard, R. S., \& McClellan, C. B. (April, 2001). Preschoolers self-report of procedural approach-avoidance. Poster presented at the Florida Conference on Child Health Psychology, Gainesville, Florida.

Cohen, L. L., McClellan, C. B., \& Bernard, R. S. (April, 2001). Infant distress by procedural phase. Poster presented at the Florida Conference on Child Health Psychology, Gainesville, Florida.

Cohen, L.L., Bernard, R.S., \& McClellan, C.B. (February, 2001). Assessment of children's approach-avoidance behavior during immunizations: A comparison of ratings and observations. Invited poster presented at the American Association for Dental Research, Morgantown, WV. 
Cohen, L. L., McClellan, C.B., \& Bernard, R. S. (November 2000). The impact of nurse-directed distraction on infant immunization distress. Poster presented at AABT Convention, New Orleans.

Cohen, L. L., Bernard, R. S., \& McClellan, C. B. (November 2000). Assessment of children's approach-avoidance behavior during immunizations: A comparison of ratings and observations. Poster presented at AABT Convention, New Orleans.

\section{INVITED SYMPOSIA/ORAL PRESENTATIONS}

Cohen, L. L., Blount, R. L., Cohen, R. J., Ball, C. M., McClellan, C. B., \& Bernard, R. S. (August, 2001). Painful medical procedures as trauma: How deep do the wounds go? In J. Faust (Chair) \& L. J. Siegel (Discussant), Trauma and Children in Health Care Settings. Symposium presented at the APA conference, Washington, D.C.

Cohen, L. L., Blount, R. L., Cohen, R. J., McClellan, C. B., Bernard, R. S., \& Ball, C. M. (August, 2000). Children's expectations and memories of acute medical distress. In D. Drotar (Chair) \& D. Faust (Discussant), Prevention and Early Intervention in Primary Care Contexts. Symposium presented at the APA conference, Washington, D.C.

\section{EDITORIAL EXPERIENCE}

Ad hoc co-reviewer, Behavior Therapy, (11/00)

Ad hoc co-reviewer, Children's Health Care, (1/01); (4/01); (10/01)

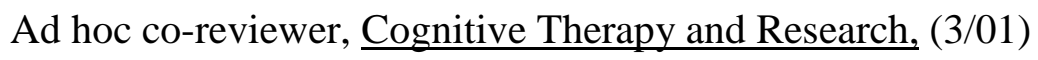

\section{CLINICAL EXPERINCE}

Quin Curtis Center Practicum, West Virginia University (7/01-present)

Trained in the administrative duties necessary to run a psychology clinic as well as continued training in the use of various therapy techniques and assessment tools with clients ranging from children to adults. Supervisor: Dr. Jeannie Sperry.

Quin Curtis Center Vertical Team Practicum, West Virginia University (8/01-present)

Trained to use various therapy techniques and assessment tools with clients ranging from children to adults. Supervisor: Dr. Martin Boone. 
Chestnut Ridge Acute Adolescent Unit, Chestnut Ridge (8/01-present)

Trained to conduct cognitive behavioral therapy groups and do individual therapy with adolescents in an acute inpatient psychiatric ward. Supervisor: Dr. Tandy McClung.

Quin Curtis Center Vertical Team Practicum, West Virginia University (8/00-8/01)

Trained to use a variety of therapy techniques and assessment tools with a variety of child and adolescent clients. Supervisor: Dr. Lindsey Cohen.

Learning Disabilities Practicum, Washington State University (1/00 - 7/00)

Conducted learning disability evaluations using standardized assessment measures on clients presenting to the psychology clinic. Supervisor: Dr. Maureen Schmitter-Edgecombe

\section{TEACHING EXPERIENCE}

Research Methods, West Virginia University, (8/00- present)

Taught three sections of a junior and senior level class. Responsible for preparing and delivering lectures, examinations, and grading APA style research projects.

Principles of Development, Washington State University (1/99-5-00)

Teaching assistant for Dr. Lindsey Cohen.

\section{REFERENCES AVAILABLE UPON REQUEST}

